Policy Research Working Paper 1679

Trade and the Accumulation and Diffusion of Knowledge

Pier Carlo Padoan
The accumulation of knowledge affects trade performance and competitiveness, but trade also (through imports) affects the accumulation of knowledge.

The World Bank

International Economics Department

International Trade Division

November 1996 


\section{Summary findings}

Padoan examines the properties of a dynamic disequilibrium model focused on trade specialization and the accumulation of knowledge. He uses a sector breakdown (four export and two import sectors) following Pavitt's (1984) taxonomy, which is especially appropriate for empirically analyzing the relationship between innovation activities and production and export performance.

Steady-state analysis shows that:

- Under perfectly balanced growth (no change in trade specialization and a uniform growth of knowledge), international diffusion of knowledge is irrelevant for growth.

- Under unbalanced growth (with changes in the structure of specialization), the process of structural change may be enhanced by the effects on the domestic accumulation of knowledge of domestic spillover, as innovation activities in one sector generate positive externalities on the rest of the economy.

The growth of foreign knowledge has an ambivalent effect on domestic performance because it is both a complement to, and a substitute for, domestic knowledge: Whenever these two effects do not perfectly match, the diffusion of international knowledge is associated with unbalanced growth. Imports of knowledge-intensive goods may not lead to higher growth unless there is sufficiently strong trade performance in the knowledge-intensive sectors (that is, there are thresholds in expansion of market share). This result, whose implications for developing countries is relevant, is not usually reported in the literature in which greater accumulation of foreign knowledge unambiguously leads to higher growth in the country that imports technology through trade.

Unbalanced growth is also associated with "output catching up." "Technological catching up" is necessary but not sufficient for balanced growth.

Parameter estimates were obtained for France, Germany, Italy, Japan, and the United Kingdom. Results appear to be consistent with theoretical expectations about the importance of "price" and "nonprice" determinants of trade performance in the four sectors. Results also seem to be generally consistent with the distribution of revealed comparative advantages in the sense that the country cases exhibit high and significant price and knowledge elasticities and high adjustment speeds - suggesting a good "capacity to deliver" in sectors with revealed comparative advantage.

Simulation exercises confirm steady-state results on the relevance of country differences in trade specialization and in the domestic accumulation of knowledge as they affect growth. They also clarify the relationship between growth and changes in the structure of trade specialization.

This paper - a product of the International Trade Division, International Economics Department - is part of a larger effort in the deparment to assess the role of technology diffusion in economic development. Copies of the paper are available free from the World Bank, $1818 \mathrm{H}$ Street NW, Washington, DC 20433. Please contact Minerva Pateña, room N5-048, telephone 202-473-9515, fax 202-522-1159, Internet address mpatena@worldbank.org. November 1996. (47 pages)

The Policy Research Working Paper Series disseminates the findings of work in progress to encourage the exchange of ideas about development issues. An objective of the series is to get the findings out quickly, even if the presentations are less than fully polished. The papers carry the names of the authors and should be used and cited accordingly. The findings, interpretations, and conclusions are the authors' otun and should not be attributed to the World Bank, its Executive Board of Directors, or any of its member countries. 


\title{
Trade and the Accumulation and Diffusion of Knowledge
}

\author{
Pier Carlo Padoan* \\ University of Rome "La Sapienza," \\ College of Europe, Bruges
}

"This paper was prepared during my stay as visiting research fellow at the International Trade Division, International Economics Department, World Bank. I would like to thank Francis $\mathrm{Ng}$, Maurice Schiff, Alan Winters, and an anonymous referee for helpful comments, and Aurora Rossodivita for research assistance. 



\section{Introduction}

Theoretical and empirical research on the relationship between trade and knowledge accumulation suggests at least two causal links: one stresses the role of knowledge accumulation in determining trade performance and competitiveness ${ }^{1}$, the other looks at the role of trade in enhancing knowledge accumulation through imports ${ }^{2}$. This paper tries to capture both elements in a unified perspective.

The approach followed is "sectoral" in the sense that it considers an economy where more than one good is produced. Two reasons can be suggested in favor of such a choice. A first one (Pasinetti 1981) stresses the role of growth in different sectors in affecting aggregate performance, because, inter alia, different rates of growth of sectoral demand will lead to growth through structural change. A second one stems from the opportunity of adopting a sectoral perspective in the investigation of the relationship between knowledge accumulation (and diffusion), dynamic comparative advantages and trade (and growth) performance. This second point is also not new. Grossman and Helpman $(1989,1990)$ and Romer (1990) consider an economy with three sectors (R\&D activity, intermediate goods, consumer goods) to study the role of knowledge accumulation and diffusion through the introduction of intermediate goods in the production of final goods. More generally, the role of intermediate goods in the knowledge diffusion process is well recognized in the literature on new growth theory ${ }^{3}$. Other more institutionally oriented approaches ${ }^{4}$ stress the role of knowledge spillovers between sectors and the consequences on trade and growth of the performance (and relative weight) of knowledge producing sectors..

\footnotetext{
1 Theoretical contributions include Grossman and Helpman (1989), (1990), Romer (1990), Verspagen (1993). Empirical contributions include Fagerberg (1988) Amable and Verspagen (1995), Amendola, Guerrieri, Padoan (1992) Magnier and Toujas-Bernate (1994)

2 Theoretical contributions include Ben David and Loewy (1995), empirical analyses include Coe and Helpman (1993), Coe, Helpman and Hoffmeister (1994), Keller (1995)

${ }^{3}$ A recent survey is offered in Fagerberg (1994) Ben David and Loewy (1995) develop a model of trade and growth where aggregate results depend on structural characteristics. While the model shows that openness enhances growth thanks to knowledge diffusion through trade it remains unclear where, in a n-country world, knowledge is produced in the first place.

${ }^{4}$ See Pavitt (1984), Dosi, Pavitt and Soete (1990), Bell, Pavitt (1995)
} 
The rest of this paper is organized as follows: paragraph 2 presents a dynamic sectoral model of trade specialization and growth, paragraph 3 discusses the steady state solution, paragraph 4 discusses estimation results for four European countries (Germany, France, Italy and the United Kingdom) and Japan, paragraph 5 discusses stability and sensitivity analysis results, paragraph 6 discusses results of some simulation exercises, paragraph 7 concludes.

\section{A Dynamic Model}

Consider an economy where firms engage in $R \& D$ activities to accumulate knowledge and increase their market shares both in domestic and foreign markets. Goods are differentiated with respect to the relevance of knowledge in determining their demand, which also depends on relative prices $^{1}$. As Maquier and Tojas-Bernate (1994) suggest, the stock of knowledge determines, in a framework of imperfect competition, the non price (quality) determinants of consumers' demand and relative shares in the international market. More specifically we may assume that the stock of knowledge is a proxy for variety. However quality influences demand with different intensity across sectors; this is captured by different knowledge elasticities (see below) ${ }^{5}$.

In the model we follow Pavitt's (1984) taxonomy to group manufacturing goods into four macrosectors. In this taxonomy ${ }^{6}$ manufacturing sectors are grouped according to the position each sector holds in the process of knowledge accumulation and diffusion, as well as on the role of knowledge and of other factors in determining performance. Thus this taxonomy, in addition to being quite suitable for the analysis of the interaction between trade and knowledge accumulation, has the advantage of providing an empirical classification of manufacturing sectors.

The four macrosectors are:

Traditional Goods. Innovative activity in this sector is limited yet necessary to allow absorption of innovations from other sectors. Process

${ }^{5}$ Amable and Verspagen (1995) find that export shares of goods belonging to different Pavitt macrosectors (see below) present different elasticities with respect to prices and technology indicators.

${ }^{6}$ Pavitt' taxonomy considers more than four sectors. Other sectors. in addition to the ones introduced in the model, are "food and agriculture" (resource intensive), energy intensive, information intensive (finance and retailing). For a recent reassessment and for the implications for development policies see Bell and Pavitt (1995). 
innovation leads to productivity gains and "price competition" is crucial. Typical sectors include clothing and footwear ${ }^{7}$

Scale Intensive Goods Innovative activity in this sector is relevant especially in process and organizational innovations. Innovation diffusion from other sectors is obtained largely through acquisition of intermediate goods. Competitiveness derives from the exploitation of scale economies. Sectors include transport equipment, consumer electronics and household appliances.

Specialized Suppliers. Innovative activity relates to both process and product innovation and is often the result of consumer-producer interaction leading to special "customer relationships " with other sectors. Competitiveness derives from "quality", mainly understood as the capacity to adapt to the users' needs both in terms of performance and prompt delivery. Sectors include machine tools and scientific instruments .

Science Based. Innovation activity through substantial R\&D investment is the main characteristic of these sectors whose competitiveness derives essentially from product innovation success. R\&D performed in these industries typically leads to knowledge spillovers to other sectors which tend to be stronger the closer is the user producer relationship. In this respect science based firms acquire knowledge from other sectors as well as disseminating it. This relationship is usually strong with specialized suppliers firms. Sectors include aerospace industries, computers, telecommunications.

\footnotetext{
${ }^{7}$ A complete classification of sectors used in this paper is available on request from the author.
} 


\section{Table 1. Model equations}

Export Share. Traditional Goods

$D \log S_{A}=\alpha_{2}\left(\log S_{A}{ }^{*}-\log S_{A}\right)$

$\log S_{A}^{*}=\log \gamma_{1}-\beta_{1} \log P$

Export Share. Scale Intensive Goods

$D \log S_{B}=\alpha_{3}\left(\log S_{B} *-\log S_{B}\right) \quad$ (2)

$\log S_{B}{ }^{*}=\log \gamma_{2}-\beta_{2} \log P+\beta_{3} \log T / T_{W}$

Export Share. Specialized Suppliers

$D \log S_{C}=\alpha_{4}\left(\log S_{C} *-\log S_{C}\right)$

$\log S_{C}{ }^{*}=\log \gamma_{3}-\beta_{4} \log P+\beta_{5} \log T / T_{W}$

Export Share. Science Based Goods

$D \log S_{D}=\alpha s\left(\log S_{D} *-\log S_{D}\right)$

$\log S_{D} *=\log \gamma_{4}+\beta_{6} \log T / T_{W}$

Knowledge Accumulation

$D \log T=\alpha_{6}\left(\log T^{*}-\log T\right)+\beta_{9} \log T_{W}+\beta_{10} \log S_{M H}$

$\log T^{*}=\log \gamma_{5}+\beta_{7} \log F+\beta_{8} \log S_{D}$

\section{Aggregate Export Share}

$D \log S_{X}=D \log S_{A}\left(S_{A} / S_{X}\right)\left(W_{A} / W\right)+\lambda_{A}\left(S_{A} / S_{X}\right)\left(W_{A} / W\right)+D \log S_{B}\left(S_{B} / S_{X}\right)\left(W_{B} / W\right)$

$+\lambda_{B}\left(S_{B} / S_{X}\right)\left(W_{B} / W\right)+D \log S_{C}\left(S_{C} / S_{X}\right)\left(W_{C} / W\right)+\lambda_{C}\left(S_{C} / S_{X}\right)\left(W_{C} / W\right)$

$+D \log S_{D}\left(S_{D} / S_{X}\right)\left(W_{D} / W\right)+\lambda_{D}\left(S_{D} / S_{X}\right)\left(W_{D} / W\right)-D \log W$ 


\section{Table 1 (cont.)}

Import Share. Traditional Goods

$D \log S_{M L}=\alpha_{7}\left(\log S_{M L}{ }^{*}-S_{M L}\right) \quad(7)$

$\log S_{M L} *=\log \gamma_{6}+\beta_{11} \log P$

Import Share. High Tech Goods

$D \log S_{M H}=\alpha 8\left(\log S_{M H} *-S_{M H}\right)$ (8)

$\log S_{M H}{ }^{*}=\log \gamma_{7}+\beta_{12} \log P-\beta_{13} \log T / T_{W}+\beta_{14} \log S_{H}$

Aggregate Import Share

$D \log S_{M}=D \log S_{M L}\left(S_{M L} / S_{M}\right)+D \log S_{M H}\left(S_{M H} / S_{M}\right)$

High Tech Export Share

$S_{X H}=S_{B}\left(W_{B} / W_{H}\right)+S_{C}\left(W_{C} / W_{H}\right)+S_{D}\left(W_{D} / W_{H}\right)(10)$

Output

$D \log Y=\alpha_{1}\left(\log Y^{*}-\log Y\right)(11)$

$\log Y^{*}=\log W+\log P_{X}+\log S_{X}-\log P_{M}-\log S_{M}$ 
Variables

endogenous

$\mathrm{S}_{\mathrm{A}}$ Export share. Traditional goods

Sв Export share. Scale intensive goods

Sc Export share. Specilalized suppliers

SD Export share. Science based goods

Sx Aggregate export share

T Stock of domestic knowledge

Y Output

SML Import share. Traditional goods

$\mathrm{S}_{\mathrm{MH}}$ Import share. High tech goods

$\mathrm{S}_{\mathrm{M}}$ Aggregate import share

Sxн Export share. High tech goods

exogenous

P Relative price

F Stock of R\& D expenditure

Tw Stock of foreign knowledge

W Total foreign demand

$\mathrm{W}_{\mathrm{i}}$ Sectoral foreign demand $(\mathrm{i}=\mathrm{A}, \mathrm{B}, \mathrm{C}, \mathrm{D}, \mathrm{H})$

Px Price of exports

$P_{M}$ Price of imports

D d/dt

The model presented in table 1 is specified as a set of (non linear) differential disequilibrium equations. The theoretical advantages of using differential equations systems have been discussed elsewhere (Gandolfo 1981, Gandolfo and Padoan 1984) here we will recall two advantages related to the empirical estimation of such models which is some relevance for the topic under discussion. One aspect is the possibility of obtaining point estimates of the adjustment speeds irrespective of the time dimension inherent in the data ${ }^{8}$. The interest for this information in the present context is twofold. First, the time lag between the production of new knowledge and its effect on trade performance is crucial in determining the overall

${ }^{8}$ Contrary to what is possible with discrete time formulations. 
performance of the economy. Secondly, the ability of domestic producers to adjust rapidly to demand is itself a factor of competitiveness.

Another, possibly more important aspect is the possibility of dealing correctly with stocks and flows ${ }^{9}$. This is particularly relevant in this context where the correct treatment of the stock of knowledge appears to be important for satisfactory empirical results ${ }^{10}$.

Let us now discuss the specific equations (see table 1). All equations are expressed as adjustment equations where each endogenous variable $X$ adjusts with a coefficient $\alpha^{11}$, to its partial equilibrium value $X^{*}$, also the disturbance terms are omitted. As mentioned above the size of adjustment speeds is also an indicator of sectoral competitiveness as it is determined, inter alia, by the "capacity to deliver", hence higher values of $\alpha$ signal higher competitiveness. Eq (1) states that the export share of traditional goods $S_{A}$ adjusts to its partial equilibrium value $S_{A}{ }^{*}$ which varies inversely with the real effective exchange rate $P$, i.e. we assume that relative technology does not directly affect international competitiveness in this sector $^{12}$. Eqs. (2)-(4) . describe the adjustment of the export market share in the three other sectors to their respective partial equilibrium values. Following Pavitt's taxonomy we assume that partial equilibrium values of the export shares for the scale intensive $(B)$ and specialized suppliers $(C)$ sectors are function of both the real effective exchange rate and of the relative stock of knowledge $T / T_{W}$, while the science based sector's share $(D)$ is function of relative knowledge alone. ${ }^{13} \mathrm{~A}$ priori, sectoral price and relative knowledge elasticities are assumed to be different. Empirical estimation results (see para. 4) show that this is not always the case, nevertheless significant country differences are present.

\footnotetext{
9 Again the reader is referred to Gandolfo (1981).

10

As shown in Verspagen (1993) the use of knowledge indicators such as patents often leads to unsatisfactory empirical results. Maquier and Toujas Bernate (1994) and Amable and Verspagen (1995) obtain much better results apparently because of their more satisfactory treatment of the variables representing the stock of knowledge. Their treatment, nevertheless, is not fully consistent with a correct of stock and flows specification in continuous time.

11 In continuous time the reciprocal of the speed of adjustment $1 / \alpha$ is the mean time lag. i.e. the time necessary for about $63 \%$ of the discrepancy between the actual and the partial equilibrium value to be eliminated. See Gandolfo (1981)

12 This is consistent with results obtained by Verspagen (1993) and by Amable and Verspagen (1995) and also by our early attempts to relate the behaviour of $S_{A}$ to the relative stock of knowledge, see below

${ }^{13}$ Both Verspagen (1993) and Amable and Verspagen (1995) find empirical support to this assumption.
} 
Eq (5) describes the process of knowledge accumulation in the economy, where the output of the knowledge production process is represented by patents. While the importance of relative knowledge in affecting trade performance is sector specific knowledge accumulation is country specific, i.e. the ability of a country to accumulate knowledge depends on specific national features involving institutional as well as economic aspects, while the pool of domestic knowledge is equally accessible to all sectors in the economy ${ }^{14}$. One assumption of the model is that it is the interaction among the innovative activity in different sectors that determines the economy-wide accumulation of knowledge. This formulation is not fully satisfactory when one chooses to adopt a sectoral perspective. A more extended modeling strategy would require to introduce sector specific as well as country specific knowledge accumulation processes and study their interaction ${ }^{15}$. However, to limit the extension of the model we leave this for future research.

In an open economy two aspects of the process of knowledge accumulation must be considered, one is related to domestic factors, the other is related to foreign factors. Both are relevant since, as suggested by Bell and Pavitt (1995) absorption of foreign knowledge always requires some form and amount of domestic knowledge production, i.e. domestic and foreign innovative efforts are, to some extent, complementary inputs in the process of domestic knowledge accumulation. While this idea is simple and self evident its modeling is far from obvious. Two approaches could be followed: one, adopted in some of the recent literature on international diffusion, ${ }^{16}$ assumes that foreign knowledge may be considered as a (partial) addition to domestic knowledge, mainly through trade; a second one, developed in the evolutionary literature on international innovation diffusion ${ }^{17}$ emphasizes the role of innovation as a process where the two sources of knowledge interact rather than simply adding up. The approach followed here tries to capture both elements of what remains, nonetheless, a topic which deserves much deeper scrutiny.

\footnotetext{
${ }^{14}$ This aspect is discussed in the literature on "national system of innovations". See e.g. Nelson (1992)

${ }^{15}$ This would require to consider e.g. both sector specific and country specific R\&D efforts, the latter possibly limited to pre-competitive research investment, as well as as sector specific patent counts. The size and empirical tractability of the model would obviously be modified.

${ }^{16}$ See e.g Ben David and Loewy (1995), Coe and Helpman (1993), Coe, Helpman and Hoffmeister (1994), Keller (1995).

${ }^{17}$ For a survey see Archibugi and Michie (1995)
} 
More specifically the idea behind eq (5) is the following. The accumulation of the stock of domestic knowledge $T$ is basically determined by a domestic effort, i.e. the partial equilibrium level of $T$ is a function of domestic variables, the -exogenous- domestic stock of R\&D expenditure, $F$, and the "size " of the science based sector in the economy, proxied by its export market share $S_{D}{ }^{18}$. The rationale for $F$ is obviously that R\&D represents the most important input in the knowledge production process. The rationale for the second variable is that, as it was made clear above, according to Pavitt's taxonomy, the science based sector generates an externality in the domestic knowledge production process. ${ }^{19}$

The two foreign variables entering equation (5), the -exogenousstock of foreign knowledge $T_{W}$, and the -endogenous- share of high tech imports $S_{M H},{ }^{20}$ do not determine the partial equilibrium level of $T$, rather one can think of eq (5) as being a linear approximation of a non linear form where the adjustment speed $\alpha_{6}$ is a function of foreign knowledge variables, i.e. $\alpha_{6}=\phi\left(T_{W}, S_{M H}\right)$. Such a formulation implies that the absorption of foreign knowledge, the intensity of which may be thought of being a function of what Abramovitz calls "social capability" ${ }^{21}$ (captured by parameters $\beta_{9}$ and $\beta_{10}$ ), increases the speed of the process of domestic knowledge accumulation. The reason why two different foreign knowledge variables are included is that the channels of international knowledge diffusion are several (indeed more than two). The recent literature on knowledge diffusion and trade ${ }^{22}$ stresses the role of imports as vehicles of diffusion, however other channels (such as foreign direct investment, R\&D cooperation, joint ventures and human capital transfers) may be just as

\footnotetext{
${ }^{18}$ Actually, the size of the science based sector should be proxied by the share of domestic production in the sector or, alternatively, by the share of science based exports in total domestic exports, rather than by $S_{D}$. Model parsimony in the first case and irrelevant differences in estimation in the second case suggested the use of $S_{D}$, allowing to gain something in analytical and empirical handling.

${ }^{19} \mathrm{Eq}(5)$ represents the accumulation of what may be defined "tangible" knowledge, thus omitting that significant part of knowledge accumulation and diffusion that is intangible and tacit. See Dosi Pavitt, and Soete 1990. While we are quite aware of this omission we would argue that at least part of the accumulation and transmission of tacit knowledge may be captured in the form of the adjustment equations where the adjustment coefficients are (also) a function of such components.

${ }^{20}$ As Keller (1996) suggests not all imports are vehicles of technology diffusion but only imports of intermediate goods. In the context of Pavitt's taxonomy this role is played by the aggregate we have defined as high tech imports

${ }_{21}^{21}$ See Abramovitz (1986) and Ben-David and Loewy (1995)

${ }^{22}$ See Coe and Helpman (1994), Coe, Helpman and Hoffmeister (1994) and Keller (1995).
} 
relevant, especially among developed countries ${ }^{23}$. The stock of foreign knowledge, $T_{W}$ can be thought of as a proxy of sources of knowledge diffusion other than imports.

Eq (6) defines the rate of change of the aggregate export share $S_{X}$. Eqs, (7)-(9) define the rate of change of import shares. For the purpose of this paper, and in order to minimize the size of the model, we do not present the four sector disaggregation for imports as well. Rather, we consider the distinction between traditional and high tech imports, where "traditional" includes the same goods defined in sector $A$ above and "high tech" includes the remaining three. Accordingly, $S_{M L}{ }^{*}$ is a function of the real effective exchange rate while $S_{M H}{ }^{*}$ is a function of both the real effective exchange rate and of the relative stock of knowledge. In addition, we assume that the high tech import share is positively related to the high tech export share $S_{X H}$ defined below (eq. 10). Equation (9) captures the fact that foreign high tech goods are both substitutes of- to the extent that imports compete in the domestic market against similar domestic goods- and complements to -to the extent that they enter as intermediate goods in domestic productiondomestic high tech goods. ${ }^{24}$ These two conflicting roles played by imports in influencing domestic growth are often neglected in the recent literature, which stresses the role of imports as vehicles of technology ${ }^{25}$.

Equation (9) defines the proportional rate of change of the aggregate import share $S_{M}$, and eq. (10) defines the level of the high tech export share.

Finally, eq. (11) defines the rate of growth of output, $D \log Y$, which is obtained by assuming trade account equilibrium ${ }^{26}$. We follow Fagerberg

${ }^{23}$ For the case of developing countries see Freeman and Hagedoorn (1994).

${ }^{24}$ In principle, the aggregate export share $S_{X}$ rather than the high tech export share $S_{X H}$ should have been considered as high tech imports enter as intermediates in traditional goods as well. The specification presented reflects some of the empirical findings discussed below. It could also be argued that the component associated with $\beta_{14}$ is redundant as domestic firms will choose between domestic and foreign intermediate goods, included in $S_{M H}$, according to their quality as proxied by the relative stock of knowledge. While this is correct in principle the sectoral aggregation chosen here is such that both complements and substitute goods are included in the same macrosector. Empirical results below confirm this assumption .

${ }^{25}$ Note that parameters $\beta_{10}, \beta_{14}$ play two different roles in the model. The first captures the intensity of spillover of high tech imports on domestic knowledge accumulation. The second captures the intensity of high tech import contents in domestic exports.

26

In its present formulation the model considers only trade in manufactures as aggregated according to Pavitt's taxonomy, hence the rate of growth of output defined here is not obtained under the assumption of full current account equilibrium. This is only an apparent limitation. Nothing prevents the extension to the other components of the current account. 
(1988) by defining first the level of output implicit in current account equilibrium $P_{X} X=P_{M} M$, where $P_{X}$ and $P_{M}$ are the export and the import price respectively, both in domestic currency, and $X$ and $M$ are the export and import quantities. Dividing and multiplying by the level of world demand, $W$, and of domestic output $Y$, respectively. the two sides of the identity above, and defining $S_{X}=X / W$ the share of domestic exports and $S_{M}=M / Y$ the share of imports over output, after rearranging, the level of output consistent with current account equilibrium (the "equilibrium output") is $Y=W P_{X} S_{X} / P_{M} S_{M}$

Taking $\operatorname{logs}$ we obtain $\log Y^{*}$ in eq. (11). The equation assumes that the rate of growth of output is the result of an adjustment mechanism (controlled by policy ) which tends to maintain current account equilibrium, and hence $Y^{*}=Y$, thus ruling away the possibility of indefinite net debt accumulation. The adjustment parameter $\alpha_{1}$ captures the intensity of the balance of payments constraint as lower values imply a slower adjustment towards the equilibrium output level and hence the possibility of e.g. running current deficits for longer periods.

\section{Steady State and Comparative Dynamics}

In this paragraph we discuss the steady state solution of the model with respect to steady state growth rates. Appendix. 1 contains the details as well as the solution for the steady state initial levels which will be used for the linearization required to perform the stability and sensitivity analysis discussed in para. 5. The analysis of the steady state growth rates and of the comparative dynamics delivers some interesting insights about the properties of the model.

We start by assuming that, in the steady state, the real exchange rate $P$ is constant, hence the export share of traditional goods, $S_{A}$ and the import share of traditional goods $S_{M L}$ do not grow. It follows that, if other sectors' shares exhibit a rate of growth different from zero, the trade specialization of the country will change. The growth rates of the four export shares are the following:

$$
\begin{aligned}
& \rho_{A}=0(12) \\
& \rho_{B}=\beta_{3}\left(\rho_{T}-\lambda_{T}\right)(13) \\
& \rho_{C}=\beta_{5}\left(\rho_{T}-\lambda_{T}\right)(14) \\
& \rho_{D}=\beta_{6}\left(\rho_{T}-\lambda_{T}\right)(15)
\end{aligned}
$$


Sectoral growth rates are zero if the rate of domestic knowledge accumulation is equal to the rate of foreign knowledge accumulation. In other words, in a world of identical technological possibilities for all countries the difference between traditional and knowledge intensive sectors is irrelevant for growth and specialization. In such a case differences between the performance of knowledge intensive sectors (B,C,D) as captured in different elasticities will also be irrelevant. On the contrary, if $\lambda_{T} \neq \rho_{T}$ the case of $\beta_{3,}, \beta_{5}, \beta_{6}$ taking on different values becomes important as the specialization structure of the economy will change. One interesting comparative dynamic exercise, therefore, is to consider the implications for the change in the specialization structure of different national economies of a higher (lower) rate of growth of foreign knowledge.

Let us now look at the steady state growth rate of domestic knowledge, which is the following $\rho_{T}=\beta_{7} \lambda_{F}+\beta_{8} \rho_{D}+\left(\beta_{9} \lambda_{T}+\beta_{10} \rho_{H}\right) / \alpha_{6}(16)$

A first information from (16) is that the larger the value of $\alpha_{6}$, the adjustment speed of $T$ to its partial equilibrium value, the less important is the role of foreign technology -through both channels of diffusion- in supporting the process of domestic knowledge accumulation. Conversely, in economies where the process of domestic knowledge accumulation is slow, the absorption of foreign knowledge plays a relevant role. The full analysis of eq. (16), however, requires that the values of $\rho_{D}$ and $\rho_{H}$ be substituted for. We will proceed in steps and substitute for the rate of growth of the science based export share first. Eq (16) becomes

$\rho_{T}=\left[\beta_{7} \lambda_{F}+\left(\beta_{9} / \alpha_{6}-\beta_{8} \beta_{6}\right) \lambda_{T}+\rho_{H} \beta_{10} / \alpha_{6}\right]\left(1-\beta_{8} \beta_{6}\right)$

The expression above yields further information: i) the rate of domestic knowledge accumulation will be higher the higher the interaction between the domestic externality effect of the growth of the $D$ sector and the elasticity of its export share to relative knowledge (the $\beta_{8} \beta_{6}$ term), i.e. the stronger the intensity of the virtuous circle between knowledge accumulation and trade performance; ii) foreign knowledge accumulation exerts an enhancing or a depressing role on domestic knowledge accumulation according to whether $\beta_{9} / \alpha_{6}><\beta_{8} \beta_{6}$ i.e. whether the positive effect of international diffusion is stronger than the negative effect of competitiveness.

Let us now turn to the determination of the rate of growth of imports in its two components. Having assumed a zero rate of growth for $P$ the rate 
of growth of traditional imports, $\rho_{L}$, is also zero. The rate of growth of high tech imports is:

$\rho_{H}=-\beta_{13} \rho_{T}+\beta_{13} \lambda_{T}+\beta_{14} \rho_{X H}$

and assuming for simplicity that $\rho_{X H}=\rho_{D}$, we obtain, after substituting and rearranging terms

$\rho_{H}=\left(\beta_{14} \beta_{6}-\beta_{13}\right)\left(\rho_{T}-\lambda_{T}\right)(17.1)$

Of course $\rho_{H}=0$ in the steady state as $\lambda_{T}=\rho_{T}$. If this is not the case then the term in the first parenthesis captures the two opposing forces on the growth of high tech imports. The positive effect accounts for the fact that a growth in domestic knowledge intensive activities (as represented by the growth of the export share of $D$ goods) requires a higher share of high tech imports (i.e. domestic and foreign high tech goods are complements). The negative effect takes into account the fact that foreign high tech goods are also substitutes of domestic high tech goods. Assuming that the term in the first parenthesis is different from zero a non-zero rate of growth of the high tech import share will result. Four possible combinations can be obtained. Let us consider briefly the two cases in which $\rho_{H}>0$. These are:

$\beta_{14} \beta_{6}>\beta_{13}$ and $\rho_{\mathrm{T}}>\lambda_{T} ; \beta_{14} \beta_{6}<\beta_{13}$ and $\rho_{\mathrm{T}}<\lambda_{T}$

The two cases describe two opposing situations. In the first case the share of high tech imports grows because domestic knowledge grows faster that foreign knowledge, hence the complementarity between the two stocks of knowledge prevails. In the second case the opposite holds as the substitution between domestic and foreign knowledge prevails. In both cases we are obviously not in a balanced growth situation and we will have opposite results on the trade specialization structure of the economy. In the first case the share(s) of knowledge intensive production(s) will grow (see eqs. 13-15), in the second case it will eventually vanish. From this point of view the relation between trade specialization and imports of knowledge intensive goods is ambiguous.

Considering (16.1) and (17.1) we can finally solve for $\rho_{T}$.

$$
\rho_{T}=\left\{\beta, \lambda_{F}+\left[\beta, / \alpha_{6}-\beta_{6}\left(\beta_{14}+\beta_{8}\right)+\beta_{13}\right] \lambda_{T}\right\} /\left[1-\beta_{8} \beta_{6}-\left(\beta_{14} \beta_{6}-\beta_{13}\right) \beta_{10} / \alpha_{6}\right]
$$

This rather cumbersome expression boils down to a clear cut point. Growth of domestic knowledge ultimately depends on domestic R\&D efforts and on absorption of foreign knowledge. However, while the first effect is straightforward the second is much more complex because of the interaction of two sets of elements: in the first place, there are two channels of transmission of foreign knowledge -imports and "direct transmission"-, 
secondly the growth of foreign knowledge produces two contrasting effects on the accumulation of domestic knowledge, a positive one insofar as it favors the expansion of the knowledge intensive sectors through knowledge diffusion, a negative one insofar as it constraints such expansion through technological competition, i.e. we come once again across the fact that domestic and foreign technology are both complements and substitutes.

From (16.2) we can derive the conditions for $\rho_{T}>0$, and $\rho_{\mathrm{T}}=\lambda_{T}$ Assuming that the denominator of (16.2) is positive $^{27}$ a positive rate of growth of domestic knowledge requires.

$\beta_{7} \lambda_{F}+\left(\beta_{9} / \alpha_{6}+\beta_{13}\right) \lambda_{T}>\beta_{6}\left(\beta_{14}+\beta_{8}\right) \lambda_{T}$

The terms on the 1.h.s. are the domestic and foreign factors affecting domestic knowledge accumulation (the foreign factors represent the complementarity of foreign and domestic knowledge), the terms on the r.h.s. represent the depressing effect of foreign knowledge accumulation (the substitution of foreign for domestic knowledge). Domestic and foreign knowledge will grow at the same rate (which, from (13)-(15) is a condition for global balanced growth) if

$\left\{1-\left[\beta_{10}\left(\beta_{14} \beta_{6}-\beta_{13}\right)-\beta_{9}\right] / \alpha_{6}+\beta_{6} \beta_{14}-\beta_{{ }_{13}}\right\} \lambda_{T}=\beta_{7} \lambda_{F}$ (18)

The domestic effort on knowledge accumulation and the net foreign knowledge accumulation must grow at the same rate ${ }^{28}$. In other words, if we assume (some form of) international knowledge diffusion, the condition for a uniform rate of growth of knowledge in all countries is not sufficient for assuring balanced growth.

We now turn to the aggregate trade share growth rates. The steady state growth rate of the aggregate export share implies

$\left(\rho_{A}+\lambda_{A}\right)=\left(\rho_{B}+\lambda_{B}\right)=\left(\rho_{C}+\lambda_{C}\right)=\left(\rho_{D}+\lambda_{D}\right)$

If $\rho_{A}=0$ from (12) balanced growth implies that all sectoral shares grow at $\lambda_{A}=\lambda_{B}=\lambda_{C}=\lambda_{D}$ and hence $\rho_{X}=0$. If we allow for unbalanced growth the rate of growth of the export share can be non zero and it is as follows

$$
\begin{aligned}
& \rho_{X}=\left(\rho_{A}+\lambda_{A}\right)\left(X / X_{A}\right)+\left(\rho_{B}+\lambda_{B}\right)\left(X / X_{B}\right) \\
& +\left(\rho_{C}+\lambda_{C}\right)\left(X / X_{C}\right)+\left(\rho_{D}+\lambda_{D}\right)\left(X / X_{D}\right)-\lambda_{W}(20)
\end{aligned}
$$

${ }^{27}$ In principal nothing can be said about the values of the parameters included in the denominator. Note however that if $\alpha_{6}$ is very small with respect to $\beta_{10}$ the denominator could be negative and, other things equal, the rate of growth of domestic knowledge could become negative. This would be the consequence of an excessively slow domestic knowledge accumulation and an excessive dependence on imports of high tech goods.

${ }^{28} \mathrm{Net}$ foreign knowledge can be defined as the total stock of foreign knowledge less the spillover effects through imports and direct diffusion. 
If we keep the assumption that the rate of growth of the traditional sector's export share is zero then, obviously, a positive value of $\rho_{x}$ implies unbalanced growth, i.e. a change in the export specialization pattern.

Balanced growth between import shares implies $\rho_{L}=\rho_{H}=0$ and from (17.1) this implies $\rho_{T}=\lambda_{T}$. Considering (16) and rearranging terms we then obtain

$\lambda_{T}\left(1+\beta_{8} \beta_{6}\right)=\lambda_{T} \beta_{9} / \alpha_{6}+\lambda_{F} \beta_{7}(21)$

Under balanced growth the depressing effect of foreign knowledge over domestic knowledge (1.h.s.) must exactly match the sum of the enhancing effect of foreign knowledge over domestic knowledge and the effect of domestic R\&D on domestic knowledge (r.h.s.). All this implies that the knowledge diffusion effect of imports is not relevant under balanced growth.

The final step is to compute the steady state growth rate of output. which is the following:

$\rho_{Y}=\lambda_{W}+\lambda_{P X}-\lambda_{P M}+\rho_{X}-\rho_{M}$

Domestic output will grow in excess of world demand, and hence we will witness a "caching-up effect", if

$\lambda_{P X}-\lambda_{P M}+\rho_{X}-\rho_{M}>0$

The expression above suggests a distinction between a "terms of trade effect" (the sum of the first two terms) and a "market share effect". If we assume constant terms of trade, $\lambda_{P M}=\lambda_{P X}$, there is no excess growth if aggregate imports and exports shares grow at the same rate. If $\rho_{X} \neq \rho_{M}$ then, given the assumption that the trade share of traditional goods does not change, we must have unbalanced growth from (20) above. Note that this result is independent from the fact that world demand for different goods grows at different rates. In other words, if technology accumulation influences trade performance differently across sectors, catching up implies a change in the specialization structure.

Finally, we can consider the relationship between "technological catching up" and "output catching up"

Technological catching up may be defined as $\rho_{T}>\lambda_{T}$, while output catching up implies $\rho_{X}>\rho_{M}$ from (22) above. Let us now consider the interaction of these two effects. To keep the analysis as simple as possible let us assume that at least one sectoral export share grows faster than the

${ }^{29}$ This distinction is analyzed in Verspagen (1993). 
import share. Assuming, as before that $\rho_{A}=\rho_{L}=0$ output catching up implies that -e.g. $-\rho_{D}>\rho_{H}$ which, given (13) and (17.1), implies

$\beta_{16}\left(\rho_{T}-\lambda_{T}\right)>\left(\beta_{6} \beta_{14}-\beta_{13}\right)\left(\rho_{T}-\lambda_{T}\right)$. Technology catching up is a necessary but not a sufficient condition for output catching up. A sufficient condition is

$\beta_{6}+\beta_{13}>\beta_{6} \beta_{14}$, i.e. the sum of the technology elasticities must be larger than the benefits in terms of export performance of the diffusion effect of technology through imports of high tech goods. Again note that output catching up implies a change in the specialization structure. 


\section{Estimation of Parameters}

The appropriate way of estimating the parameters is to carry out the estimation of the non linear model (1)-(11) through simultaneous methods (FIML) as is the usual procedure in dealing with continuous time econometric models (see Gandolfo 1981). However, this is not possible in our case due to degree of freedom limitations ${ }^{30}$ so the following two-step procedure was followed and applied to the four major European countries Germany, France, Italy and the United Kingdom- as well as to Japan. In the first step sectoral export share equations (1)-(4) and sectoral import share equations (7)-(8) were estimated in pairs ${ }^{31}$ (FIML) so as to obtain initial values of parameters and to check for significant differences between elasticities. Once estimates for parameters for these equations were obtained the model (1)-(10) -linearized about sample means ${ }^{32}$ - was estimated with parameters entering eqs. (1)-(4) and (7)-(8) constrained to take on the values obtained in the first step of the estimation procedure. The second step has allowed to obtain the estimates of the parameters entering eq. (5). Parameter estimates presented in tables 3 and 4 are the results of the two step procedure with asymptotic standard errors in parenthesis. Some of the parameters (denoted by ${ }^{*}$ ) were constrained to take on a given value in the first step of the estimation either because they did not result to be significantly different from the value imposed during early stages of estimation or because they increased the efficiency of the estimates. All point estimates are significant at least at the $5 \%$ level and have the correct sign. Carter-Nagar system $R_{W}^{2}$ statistics (Carter and Nagar 1977) are quite acceptable and the associated $\chi^{2}$ values in all cases reject the hypothesis that the model as a whole is not consistent with the data. Both statistics are

\footnotetext{
${ }^{30}$ See Appendix 2 for details on data.

In the case of France three sectoral export equations were estimated simultaneously.

${ }^{32}$ Equation (11), which defines the rate of growth of output, was not included in the estimation procedure. This equation was, however, used in both stability analysis (para. 5) and simulations (para .6) imposing the value of 0.5 on the adjustment coefficient $\alpha_{1}$. The estimation of the linearized model was performed using Cliff Wymer's RESIMUL program for the estimation of the approximate discrete analogue of the original continuous time model. Wymer's ESCONA program allows for the FIML estimation of the original non linear model. Previous experiments on other models (see De Arcangelis et al 1996) show that the improvement in estimation results when using ESCONA rather than RESIMUL do not exceed the costs of much lengthier and costlier computation procedures when non linearities pertain to definitional equations as in the present case.
} 
presented at the bottom of table 4 and they are related to the full version of the model, containing eqs. (1)-(10).

The discussion of the results is best carried out by looking at the different national cases. Each national case will be considered by looking both at its sectoral trade competitiveness (parameters entering eqs, (1)-(4) and (7)-(8) $)$ and at the features of the knowledge accumulation process (parameters entering eq (5)). Results will be compared with the structure of revealed comparative advantages (RCA) in the four Pavitt macrosectors as reported in table $2^{33}$ so as to check to what extent our estimates are

\section{Table 2 Revealed Comparative Advantages: France, Germany, Italy, Japan, UK. Pavitt macrosectors}

$\underset{\mathrm{y}}{\mathrm{F} \text { rance German }}$ Italy Japan UK

$\begin{array}{cccccc}\text { Traditional } & 0.96 & 0.96 & 2.2 & 0.66 & 0.87 \\ \text { Scale Int. } & 1.21 & 1.37 & 0.89 & 1.62 & 0.98 \\ \text { Spec Sup. } & 1.4 & 2.06 & 1.87 & 2.37 & 1.62 \\ \text { Science B. } & 1.1 & 1.03 & 0.72 & 1.96 & 1.39\end{array}$

Source: see Appendix 2

consistent with the distribution of RCA's over the sample period. Before looking at the specific cases the following general comments can be made: i) results appear to be consistent with theoretical expectations about the importance of "price" and "non price" determinants of trade performance in the four macrosectors ${ }^{34}$; ii) results also seem to be generally consistent with the distribution of RCA in the sense that the country cases exhibit high and

\footnotetext{
${ }^{33}$ RCA are defined as $\left(X_{i j} / X_{j w}\right) /\left(X_{j} / X_{w}\right)$, where $X=$ exports, $i=$ sector, $j=$ country, w=world. $A$ value greater that 1 indicates the presence of a revealed comparative advantage in sector $i$.

${ }^{34}$ Amable and Verspagen (1995) also find some consistency between theoretical expectations and empirical results about the determinants of sectoral export share performance when sectors are grouped according to Pavitt's taxonomy. In our case attempts to find effects of relative knowledge on the export share performance in traditional goods never led to significant results.
} 
significant price and/or knowledge elasticities and high adjustment speeds, suggesting a good "capacity to deliver", in the sectors where RCA are present;

Table 3. Point estimates of adjustment parameters. Asymptotic standard errors in parenthesis

$\begin{array}{llllll} & \text { Germany } & \text { France } & \text { Italy } & \text { Japan } & \text { UK } \\ \alpha_{1} & - & - & - & - & - \\ \alpha_{2} & 1,325 & 0.912 & 0.828 & 0.432 & 1.796 \\ & (0.323) & (0.137) & (0.201) & (0.105) & (0.370) \\ \alpha_{3} & 0.563 & 0.808 & 1.072 & 2.484 & 0.704 \\ & (0.427) & (0.122) & (0.384) & (0.058) & (0.398) \\ \alpha_{4} & 1.624 & 0.388 & 2.243 & 0.280 & 1.908 \\ & (0.427) & (0.122) & (0.384) & (0.058) & (0.398) \\ \alpha_{5} & 0.561 & 0.956 & 1.780 & 0.260 & 0.261 \\ & (0.155) & (0.173) & (0.486) & (0.093) & (0.094) \\ \alpha_{6} & 0.322 & 0.267 & 0.248 & 0.686 & 0.452 \\ & (0.079) & (0.049) & (0.071) & (0.172) & (0.133) \\ \alpha_{7} & 1.651 & 0.951 & 0.869 & 1.011 & 1.332 \\ & (0.393) & (0.221) & (0.142) & (0.288) & (0.309) \\ \alpha_{8} & 1.236 & 0.772 & 0.618 & 1.240 & 0.395 \\ & (0.329) & (0.203) & (0.219) & (0.293) & (0.173)\end{array}$

iii) in several cases sectoral price and knowledge elasticities appeared to be not significantly different and were constrained to take on the same value in final stages of estimation ${ }^{35}$, this indicates that the sectoral disaggregation followed is not always fully relevant, however aggregation differs across countries; iv) drawing on results discussed in para 3 significantly different knowledge elasticities -when present- suggest that in all country cases there is a tendency to a modification in the trade specialization

${ }^{35}$ This is shown in table 4 whenever the parameter symbol replaces the point estimate. 
structure, however this tendency remains overall moderate (as one should expect $^{36} v$ ) results indicate relevant country differences in the process of knowledge accumulation and different degrees of exposure to international knowledge diffusion, consistently with the assumption of "national systems of innovation" (Nelson 1992).

Germany The relative price elasticities in the traditional and scale intensive sectors were constrained to take on the same value, which is smaller than one, while the price elasticity in the specialized suppliers sector was constrained to take on the value of one. Technology elasticities in the specialized suppliers and science based sectors were also constrained to take on the same value which turns out to be smaller with respect to other cases (and especially with respect to the UK case which shows the same pattern of elasticity aggregation). These results are partly consistent with the distribution of RCA in Germany which shows a strong advantage in specialized suppliers (see table 2). Competitiveness in this macrosector is also confirmed by the high value of $\alpha_{4}$, the sectoral adjustment speed .

Estimates of parameters entering eq (5) show a moderate elasticity of patenting with respect to R\&D expenditure, but also an important domestic spillover effect, a moderate role of the stock of foreign knowledge $\mathrm{e}^{37}$ but a more relevant role of high tech imports in enhancing domestic knowledge accumulation; this last point is confirmed by the relatively high elasticity of the high tech import share to the high tech export share

France is the only case where the three knowledge elasticities are not significantly different and so in the first step of the estimation they were constrained to take on the same value which is also one the highest knowledge elasticity obtained. This result suggest a high degree of integration among the knowledge sensitive sectors $\mathrm{B}, \mathrm{C}, \mathrm{D}$, and is consistent with the RCA structure in the

${ }^{36}$ It should be recalled that this result, which implies different rates of growth in sectoral export market shares, requires that the rate of growth of domestic knowledge be different from the rate of growth of foreign knowledge.

${ }^{37}$ In the case of Germany the stock of foreign knowledge excludes patents granted to US and Japanese firms (i.e. it includes only patents granted to European firms in the US, see Appendix 2 for details). Different definitions of the variable $T_{W}$ were tried in estimation for all national cases but with the exception of Germany the best results were obtained with the "world "stock of patents. 
Table 4. Point estimates of other parameters. Asymptotic standard errors in parenthesis

Germany France Italy Japan UK

$\begin{array}{llllll}\beta_{1} & 0.266 & 1.506 & 1.686 & 1.240 & 0.395 \\ & (0.108) & (0.381) & (0.498) & (0.293) & (0.173) \\ \beta_{2} & \beta_{1} & \beta_{1} & \beta_{1} & 0.0^{*} & 1.661 \\ & & & & & (0.680) \\ \beta_{3} & 0.1^{*} & 0.104 & 0.039 & 0.060 & 0.074 \\ & & (0.012) & (0.0036) & (0.025) & (0.018) \\ \beta_{4} & 1.0^{*} & 2.05 & 0.0^{*} & \beta_{1} & 0.0^{*} \\ \beta_{5} & 0.073 & \beta_{3} & 0.117 & 0.069 & 0.122 \\ & (0.010) & & (0.030) & (0.027) & (0.028) \\ \beta_{6} & \beta_{5} & \beta_{3} & 0.0217 & \beta_{3} & \beta_{5} \\ & & & (0.0045) & & \\ \beta_{7} & 0.031 & 0.016 & 0.058 & 0.070 & 0.072 \\ & (0.0043) & (0.0027) & (0.0019) & (0.0051) & (0.029) \\ \beta_{8} & 0.014 & 0.007 & 0.005 & 0.006 & 0.0096 \\ & (0.0029) & (0.0012) & (0.0019) & (0.0011) & (0.002) \\ \beta_{9} & 0.013 & 0.085 & 0.0^{*} & 0.0^{*} & 0.117 \\ & (0.0061) & (0.015) & & & (0.035) \\ \beta_{10} & 0.036 & 0.020 & 0.017 & 0.023 & 0.047 \\ & (0.0079 & (0.0055) & (0.003) & (0.008) & (0.012) \\ \beta_{11} & 0.5^{*} & 0.5^{*} & 0.5^{*} & 0.5^{*} & 0.5^{*} \\ \beta_{12} & 0.1^{*} & 0.1^{*} & 0.1^{*} & 0.1^{*} & 0.1^{*} \\ \beta_{13} & 0.047 & 0.068 & 0.025 & 0.051 & 0.067 \\ & (0.0106) & (0.015) & (0.0061) & (0.014) & (0.015) \\ \beta_{14} & 0.451 & 0.122 & 0.281 & 0.151 & 0.211 \\ & (0.196) & (0.031) & (0.076) & (0.048) & (0.043)\end{array}$


Table 4 (cont.)

\begin{tabular}{|c|c|c|c|c|c|}
\hline$\gamma_{1}$ & $\begin{array}{l}1.956 \\
(0.271)\end{array}$ & $\begin{array}{l}0.561 \\
(0.095)\end{array}$ & $\begin{array}{l}0.060 \\
(0.026)\end{array}$ & $\begin{array}{l}0.343 \\
(0.231)\end{array}$ & $\begin{array}{l}0.976 \\
(0.442)\end{array}$ \\
\hline$\gamma_{2}$ & $\begin{array}{l}0.971 \\
(8.821)\end{array}$ & $\begin{array}{l}0.459 \\
(0.077)\end{array}$ & $\begin{array}{l}1.374 \\
(0.202)\end{array}$ & $\begin{array}{l}2.256 \\
(0.451)\end{array}$ & $\begin{array}{l}1.590 \\
(0.318)\end{array}$ \\
\hline$\gamma_{3}$ & $\begin{array}{l}1.572 \\
(0.175)\end{array}$ & $\begin{array}{l}0.255 \\
(0.117)\end{array}$ & $\begin{array}{l}0.078 \\
(0.031)\end{array}$ & $\begin{array}{l}0.038 \\
(0.011)\end{array}$ & $\begin{array}{l}0.233 \\
(0.105)\end{array}$ \\
\hline$\gamma_{4}$ & $\begin{array}{l}1.379 \\
(0.175)\end{array}$ & $\begin{array}{l}1.161 \\
(0.147)\end{array}$ & $\begin{array}{l}0.964 \\
(0.155)\end{array}$ & $\begin{array}{l}1.902 \\
(0.416)\end{array}$ & $\begin{array}{l}0.216 \\
(0.101)\end{array}$ \\
\hline$\gamma_{5}$ & $\begin{array}{l}0.186 \\
(0.083)\end{array}$ & $\begin{array}{l}0.412 \\
(0.024)\end{array}$ & $\begin{array}{l}0.014 \\
(0.0023)\end{array}$ & $\begin{array}{l}0.110 \\
(0.045)\end{array}$ & $\begin{array}{l}1.580 \\
(0.153)\end{array}$ \\
\hline$\gamma_{6}$ & $\begin{array}{l}0.953 \\
(0.181)\end{array}$ & $\begin{array}{l}2.275 \\
(0.981)\end{array}$ & $\begin{array}{l}0.065 \\
(0.015)\end{array}$ & $\begin{array}{l}0.256 \\
(0.211)\end{array}$ & $\begin{array}{l}0.086 \\
(0.041)\end{array}$ \\
\hline$\gamma_{7}$ & $\begin{array}{l}0.816 \\
(0.571)\end{array}$ & $\begin{array}{l}1.214 \\
(0.560)\end{array}$ & $\begin{array}{l}1.031 \\
(0.915)\end{array}$ & $\begin{array}{l}2.111 \\
(0.910)\end{array}$ & $\begin{array}{l}0.717 \\
(0.516)\end{array}$ \\
\hline$R_{W}^{2}$ & 0.729 & 0.663 & 0.699 & 0.550 & 0.613 \\
\hline $\begin{array}{l}\chi^{2} \\
\text { (d.o.f }\end{array}$ & $\begin{array}{l}432 \\
(17)\end{array}$ & $\begin{array}{l}314 \\
(17)\end{array}$ & $\begin{array}{l}366 \\
(17)\end{array}$ & $\begin{array}{l}180 \\
(17)\end{array}$ & $\begin{array}{l}254 \\
(17)\end{array}$ \\
\hline
\end{tabular}

same sectors (see table 2 ). The relatively strong domestic spillover effect $\left(\beta_{8}\right)$ is also consistent with a high degree of integration among knowledge sensitive sectors. Two of these three sectors also exhibit high adjustment speeds. On the contrary, the point estimate of $\alpha_{6}$ suggests a slow process of domestic knowledge accumulation. Contrary to the case of Germany the elasticity to domestic R\&D accumulation is low while the influence of the world stock of knowledge is much more important with imports of high tech goods playing a somewhat more limited role; this is also confirmed by a relatively low value of $\beta_{14}$, the elasticity of high tech imports to high tech exports. In sum, the non trade channels of international knowledge diffusion seem to play a relevant role in the case of France

Italy. As in the previous two cases $\beta_{1}$ and $\beta_{2}$, the price elasticities in the A,B sectors, were constrained to take on the same value, which is also the highest among the five country cases: the price elasticity in the specialized supplier sector was constrained to zero while the estimate of knowledge elasticity in the same sector as well as of the adjustments speed turned out to be very high, consistently with Italy's strong specialization in this macrosector. The weak specialization in scale intensive products seems 
to account for the low knowledge elasticity. Note that Italy is the only country case where the knowledge elasticities turned out to be significantly different (and low with the exception of $\beta_{5}$ ) suggesting a weak integration among the knowledge sensitive sectors.

The knowledge accumulation equation shows a high elasticity to domestic R\&D, a limited domestic spillover effect (again a sign of low integration among knowledge sensitive sectors) a modest effect of international diffusion limited to high tech imports and no effect of the world stock of knowledge as $\beta$, was constrained to zero in the early stage of estimation. To some extent Italy's model of knowledge accumulation appears to be closer to the German than to the French (and UK's, see below) case $^{38}$.

United Kingdom The knowledge elasticities in sectors C,D turned out not to be significantly different and were constrained to take on the same value which is also quite high consistently with the country's specialization (see table 2). The knowledge elasticity in the scale intensive sector is also relatively high but significantly smaller. Contrary to the other European cases, price elasticities turned out to be all significantly different from one another.

The process of knowledge accumulation strikes out as being quite different from the other European cases as well as from Japan's. It appears to be the fastest of the four European cases, highly sensitive to domestic R\&D and with a very strong domestic spillover effect. It also seems to benefit more strongly from international diffusion, both through high tech imports and through the effects of the foreign stock of knowledge. In sum the UK model of knowledge accumulation seems to be efficient and highly integrated in the international economy, also as a consequence. of the strong presence of foreign multinationals ${ }^{39}$

Japan. As one might expect Japan is different from all the other cases considered. Price elasticity is high and not significantly different in traditional and specialized suppliers sectors while it turned out not to be significantly different from zero in the scale intensive sector where competitiveness seems to be associated to an extremely high capacity to deliver (very high value of $\alpha_{3}$ ) and a high knowledge elasticity, itself not

\footnotetext{
${ }^{38}$ Amendola, Guerrieri and Padoan (1992) find that Italy's technological specialization structure is not related to her trade specialization structure.

${ }^{39}$ See Perez (1995)
} 
significantly different from the knowledge elasticity in the science based sector $^{40}$. This suggest an integration between scale intensive and science based sectors -a peculiar feature of the Japanese economy- which are also two macrosectors where Japan shows a very strong specialization -see table 2.

The knowledge accumulation equation shows the highest adjustment speed among the five cases considered and a very high elasticity to domestic R\&D. The relative closeness of the Japanese model of knowledge accumulation -as well as the very limited presence of foreign multinationals - is reflected in the low values of $\beta_{10}$ and $\beta_{14}$ as well as in the fact that $\beta_{9}$, the parameter associated with the foreign stock of knowledge, was constrained to zero in the early stages of estimation .

\section{Stability and Sensitivity}

In this paragraph we discuss the (local) stability and sensitivity properties of the five estimated country models. Stability analysis ${ }^{41}$ is performed using the linear approximation about the steady state of the non linear model (1)(11) (See Appendix 1). Before discussing the results let us consider the importance of stability analysis in the present context. The model presented here is not a full macroeconomic model so the question one asks when performing stability analysis is not whether the national economies considered present an overall stable behavior but, rather, whether the trade and knowledge sections of these economies converge to their steady state; if the answer is yes we can interpret the result in the sense that the trade and knowledge specialization structure is a stable equilibrium, if the answer is no then forces are at work in the system that drive it away from its steady state trade and knowledge specialization configuration.

Additional information about the robustness of the specialization structures can be obtained through sensitivity analysis. By sensitivity analysis I mean the analysis of the effects of the changes in the parameters of the model on the characteristic roots of the model ${ }^{42}$. This can be performed in a general way by computing the partial derivatives of these

\footnotetext{
${ }^{40}$ Note that, contrary to the findings of e.g. Maquier, Tojas-Bernate (1994) knowledge elasticities for Japan are not dramatically higher with respect to other advanced countries.

${ }^{41}$ Stability and sensitivity are carried out through Cliff Wymer's CONTINEST program.

${ }^{42}$ For a more detailed analysis see Gandolfo (1981) para.2.2.4.
} 
roots with respect to the parameters. If we call the matrix of the linear approximation to the original non-linear system $A$ we can compute $\partial \mu_{i} / \partial \boldsymbol{A}$, where $\mu_{i}$ denotes the $i$ th characteristic root of $\boldsymbol{A}$. A system of differential equations is structurally stable if slight changes in its coefficients do not change its stability properties; the availability of the partial derivatives $\partial \mu_{i} / \partial \theta_{j}$, where $\theta_{j}$ denotes the $j$ th parameter, enables us to check the structural stability straightforwardly, at least at the local level. The same partial derivatives enable us to determine possible bifurcations, namely the values of the parameters at which a qualitative change in the nature of equilibrium occurs. In fact, to a first approximation, $\mathrm{d} \mu_{\mathrm{i}}=\sum j\left(\partial \mu_{i} / \partial \theta_{j}\right) \mathrm{d} \theta_{j}$, or, if only one particular critical parameter is to be considered, $\mathrm{d} \mu_{\mathrm{i}}=\left(\partial \mu_{i} / \partial \theta_{j}\right) \mathrm{d} \theta_{\mathrm{j}}$. Therefore, if $\mu_{i} \neq 0$, letting $\mu_{\mathrm{i}}+\mathrm{d} \mu_{\mathrm{i}}=0$, we can determine the corresponding $\mathrm{d} \theta_{j}=-\mu_{i} /\left(\partial \mu_{i} / \partial \theta_{j}\right) \mathrm{d} \theta_{j}$, and so the neighborhood of the bifurcation value of the $j$ th parameter, $\theta_{j}+\mathrm{d} \theta_{j}$.

In what follows we discuss the results of the stability and sensitivity analysis for the five country models considering each national case as, once, again national differences are of some relevance. Table 5 presents the characteristic roots, damping periods and periods of cycle ${ }^{43}$ for the five country cases. Tables 6-10 present sensitivity results for selected parameters (i.e. parameters which crucially affect the dynamic properties of the model).

Given the results, it is convenient to look at two groups of countries separately,

with France and UK forming a different group: the reason is simple, these two latter

\footnotetext{
${ }^{43}$ The damping period is the time required for about $63 \%$ of the initial deviation to be eliminated (of course it is defined only for stable roots). The period of cycle is defined only for complex roots.
} 


\begin{tabular}{|c|c|c|c|c|c|c|c|c|c|c|c|}
\hline \multicolumn{3}{|l|}{ France } & \multicolumn{3}{|c|}{ Germany } & \multicolumn{2}{|l|}{ Italy } & \multicolumn{2}{|l|}{ Japan } & \multicolumn{2}{|l|}{ UK } \\
\hline c.r & i.p & d.p & p.c & c.r & d.p & c.r & d.p & c.r & d.p & c.r & d.p \\
\hline 0.189 & & & & -0.0115 & 86.96 & -0.0217 & 46.08 & -0.0376 & 26.595 & 0.21 & \\
\hline-0.0205 & & 48.78 & & -0.176 & 5.68 & -0.1257 & 7.955 & -0.05178 & 19.312 & -0.0417 & 23.98 \\
\hline-0.2049 & & 4.88 & & -0.4819 & 2.075 & -0.17 & 5.88 & -0.2392 & 4.18 & -0.2968 & 3.368 \\
\hline-0.5 & & 2 & & -0.5 & 2 & -0.2558 & 3.908 & -0.3088 & 3.238 & -0.4811 & 2.078 \\
\hline-0.512 & & 1.95 & & -0.51 & 1.961 & -0.5 & 2 & -0.42 & 2.381 & -0.5 & 2 \\
\hline-0.5922 & & 1.688 & & -0.56 & 1.786 & -0.50012 & 1.999 & -0.5 & 2 & -0.573 & 1.745 \\
\hline-0.8 & & 1.25 & & -0.576 & 1.735 & -0.5028 & 1.989 & -0.512 & 1.953 & -0.71 & 1.408 \\
\hline-0.88 & & 1.136 & & -1.32 & 0.785 & -0.83 & 1.205 & -0.5215 & 1.917 & -0.724 & 1.38 \\
\hline-0.7509 & 0.2964 & 1.332 & 21.194 & -1.3315 & 0.751 & -1.07 & 0.935 & -0.58 & 1.723 & -1.79 & 0.559 \\
\hline-0.7509 & -0.2964 & 1.332 & 21.194 & -1.59 & 0.629 & -2.239 & 0.447 & -2.4 & 0.417 & -1.808 & 0.553 \\
\hline
\end{tabular}

cases display an unstable root (see table 5) while the other three cases present only stable roots. For the three stable country cases -Germany, Italy and Japan- information of some interest can be obtained from sensitivity analysis results (tables $6,8,9$ ). First of all it can be noted that adjustments coefficients in the sectoral export shares have a stabilizing effect, i.e. their increase moves the root away from the bifurcation value, in all three cases (the only exception being $\alpha_{5}$ in the case of Japan); the same can be said of $\alpha_{6}$, the adjustment speed in the knowledge accumulation process. One interpretation of this result is that a stronger ability to deliver, which can be considered as a sign of stronger competitiveness, stabilizes the specialization structure. Ambiguous effects on stability (in the sense that an increase in their value stabilizes some roots while destabilizing others) are generated, again in all three cases, by changes in $\beta_{5}$ and $\beta_{10}$, respectively the knowledge elasticity in the science based export share and the coefficient of high tech imports in the knowledge accumulation equation,. This effect is also present in the case of Japan for $\beta_{3}$, the knowledge elasticity in the scale intensive sector. Considering that, in the case of Germany and Japan, these elasticities are constrained to be the same in more than one sector one interpretation is that a very high knowledge elasticity in knowledge sensitive sectors may, eventually, lead to a change in the specialization structure. 
Table 6. Sensitivity analysis with respect to selected parameters. Germany

Root $(\mu) \quad \partial \mu / \partial \alpha_{3} \quad \partial \mu / \partial \alpha_{4} \quad \partial \mu / \partial \alpha_{5} \quad \partial \mu / \partial \alpha_{6} \quad \partial \mu / \partial \alpha_{8}$

$-0.4819-1.0$

$-0.1444$

$-0.5765$

$-0.8575$

$-0.2124$

$-1.3315$

$-1.0415$

$-1.59$

$\begin{array}{llrr}\text { Root }(\mu) & \partial \mu / \partial \beta_{5} & \partial \mu / \partial \beta_{10} & \partial \mu / \partial \beta_{14} \\ -0.4819 & 0.2149 & 0.4089 & 0.011\end{array}$

$\begin{array}{lll}-0.5765 & -0.1792 & -0.3915\end{array}$

$-1.3315$

$-1.59$

0.143

0.2883

Table7. Sensitivity analysis with respect to selected parameters. France

$\operatorname{Root}(\mu) \quad \partial \mu / \partial \alpha_{4} \quad \partial \mu / \partial \alpha_{5} \quad \partial \mu / \partial \alpha_{6} \quad \partial \mu / \partial \alpha_{8}$

0.189

$-0.2049$

$-0.9395$

$-0.5923$

$-1.2790$

$-0.3694$

$-0.7909$

0.6524

$-0.4185$

$\pm 0.2965 i$

Root $(\mu)$

0.189

$\partial \mu / \partial \beta_{3}$

$\partial \mu / \partial \beta_{9}$

$\partial \mu / \partial \beta_{13}$

$\partial \mu / \partial \beta_{14}$

$-0.2049$

$-0.5923$

1.2072

$-0.1959$

0.1541

0.1078

$-0.7909$

0.459

$\pm 0.2965 i$

0.198 
Table 8. Sensitivity analysis with respect to selected parameters. Italy

Root $(\mu) \quad \partial \mu / \partial \alpha_{4} \quad \partial \mu / \partial \alpha_{5} \quad \partial \mu / \partial \alpha_{6}$

$-0.1701 \quad-0.8116-0.1134$

$\begin{array}{lll}-0.2559 & -0.2131 & -0.8756\end{array}$

$-0.83$

$-2.2392 \quad-1.0005$

Root $(\mu) \quad \partial \mu / \partial \beta_{5} \quad \partial \mu / \partial \beta_{10} \quad \partial \mu / \partial \beta_{13}$

$\begin{array}{lll}-0.1701 & 0.077 & 0.4691\end{array}$

$\begin{array}{lll}-0.2559 & -0.0522 & -0.3783\end{array}$

$\begin{array}{lll}-0.83 & -0.1663 & 0.0342\end{array}$

$-2.2392$

Table 9. Sensitivity analysis with respect to selected parameters. Japan

Root $(\mu) \quad \partial \mu / \partial \alpha_{4} \quad \partial \mu / \partial \alpha_{5} \quad \partial \mu / \partial \alpha_{6} \quad \partial \mu / \partial \alpha_{8}$

$\begin{array}{lll}-0.2392 & -0.3004 & -0.5683\end{array}$

$\begin{array}{lll}-0.3088 & -0.7386 & -0.3955\end{array}$

$\begin{array}{ll}-0.5215 & 0.4214\end{array}$

$-0.5804 \quad-1.4076$

0.4313

Root $(\mu) \quad \partial \mu / \partial \beta_{3} \quad \partial \mu / \partial \beta_{5} \quad \partial \mu / \partial \beta_{10}$

$\begin{array}{llll}0.2392 & 0.0658 & 0.2079 & 0.7199\end{array}$

$\begin{array}{llll}-0.3088 & 0.0727 & -0.2797 & -0.7134\end{array}$

$\begin{array}{lll}-0.5215 & -0.5513 & -1.3056\end{array}$

$\begin{array}{lll}-0.5804 & 0.4128 & 1.2991\end{array}$ 
Table10. Sensitivity analysis with respect to selected parameters. UK

Root $(\mu) \partial \mu / \partial \alpha_{6} \quad \partial \mu / \partial \alpha_{8}$

0.2108

$-0.2969-0.4505$

$-0.4812 \quad-0.4133$

$-0.7245$

$-1.5682$

$-1.8081$

Root $(\mu)$

$\partial \mu / \partial \beta_{5} \quad \partial \mu / \partial \beta_{9}$

$\partial \mu / \partial \beta_{13} \quad \partial \mu / \partial \beta_{14}$

0.2108

1.1175

$-0.1657$

0.1273

0.1099

$-0.2969$

0.1371

$-0.4812$

0.394

$-0.7445$

$\begin{array}{ll}-0.7245 & -2.2961\end{array}$

$-1.8081 \quad 0.9764$

Let us now consider the two other country cases, France and the UK. They both present one positive root (see table 5) indicating an unstable behavior. The case for France is also the only one where complex roots are present indicating a cyclical growth pattern.

The mechanics of the unstable behavior can be clarified by performing the dynamic simulation of the original non linear model (1)-(11) (see next paragraph) in the French and UK cases. The pattern, that is quite similar in the two cases, is as follows: due to slow growth of the domestic stock of knowledge relative to the stock of foreign knowledge market shares in the three knowledge sensitive sectors start to decline; this effect is particularly strong in the case of France where the knowledge elasticity is constrained to be the same in the three sectors. This, after a lag, feeds back on domestic knowledge accumulation through the domestic spillover effect $-\beta_{8}$ - and leads to a fall in $T$, itself feeding back on export share decline. Different knowledge elasticities and spillover parameters (as well as different adjustment speeds) produce different timings of the turning point in the behavior of $T$, after 40 periods (years) in the case of France and after 44 periods in the UK case.

Sensitivity analysis provides additional information as well as indications about stabilizing factors. In both cases (see tables 7 and 10) an increase in the knowledge elasticities in the knowledge sensitive sectors is destabilizing. This last result is intuitive as an increase in these elasticities would strengthen the negative effect of the relative (and then absolute) decline in domestic knowledge. The only parameter that exerts a significant 
stabilizing effect on the positive root is, again in both cases, $\beta_{9}$, the parameter associated with the diffusion effect of foreign knowledge on domestic knowledge. Again the intuition is clear. A stronger spillover effect mitigates -and eventually eliminates- the negative consequences on trade performance and knowledge accumulation of an inadequate growth of $T$. This is consistent with steady state results pointing to the "ambiguous" effect of foreign knowledge on domestic performance. From (21) above we know that an increase in $\beta_{9}$ helps to resume balanced knowledge growth thus offsetting the unstable behavior discussed here. To conclude this point, it is not by chance that France and UK display a much stronger effect of $T_{W}$ on $T$ and that they also present higher values for the knowledge elasticities, pointing to a deeper "technological integration". Sensitivity results suggest that, in order to eliminate instability -which may interpreted as the result of an insufficient effort in domestic knowledge accumulation given the trade specialization pattern- the only solution is to increase technological integration.

\section{Simulations}

In this section we present the results of a number of simulation exercises for the purpose of a better understanding the properties of the model. The simulations have been performed by solving the original non linear model (1)-(11) through Cliff Wymer's APREDIC program. The five simulation exercises presented here ${ }^{44}$ will be discussed separately looking at the behavior of output, export market shares and the stock of domestic knowledge $(T)$. Figs 1-5 report differences in output levels from the base run. Table 11 reports percentage changes with respect to the base run in export market shares and in the level of $T$ at the end of the simulation run (20 periods $=$ years). Overall, simulations confirm the relevance of differences in both trade specialization and in domestic knowledge accumulation processes in affecting growth and clarify the relationship between growth performance and changes in the structure of trade specialization, as well as the ambiguous relationship between trade. knowledge and growth

${ }^{44}$ Other simulation exercises were carried out and not presented for brevity's sake. 


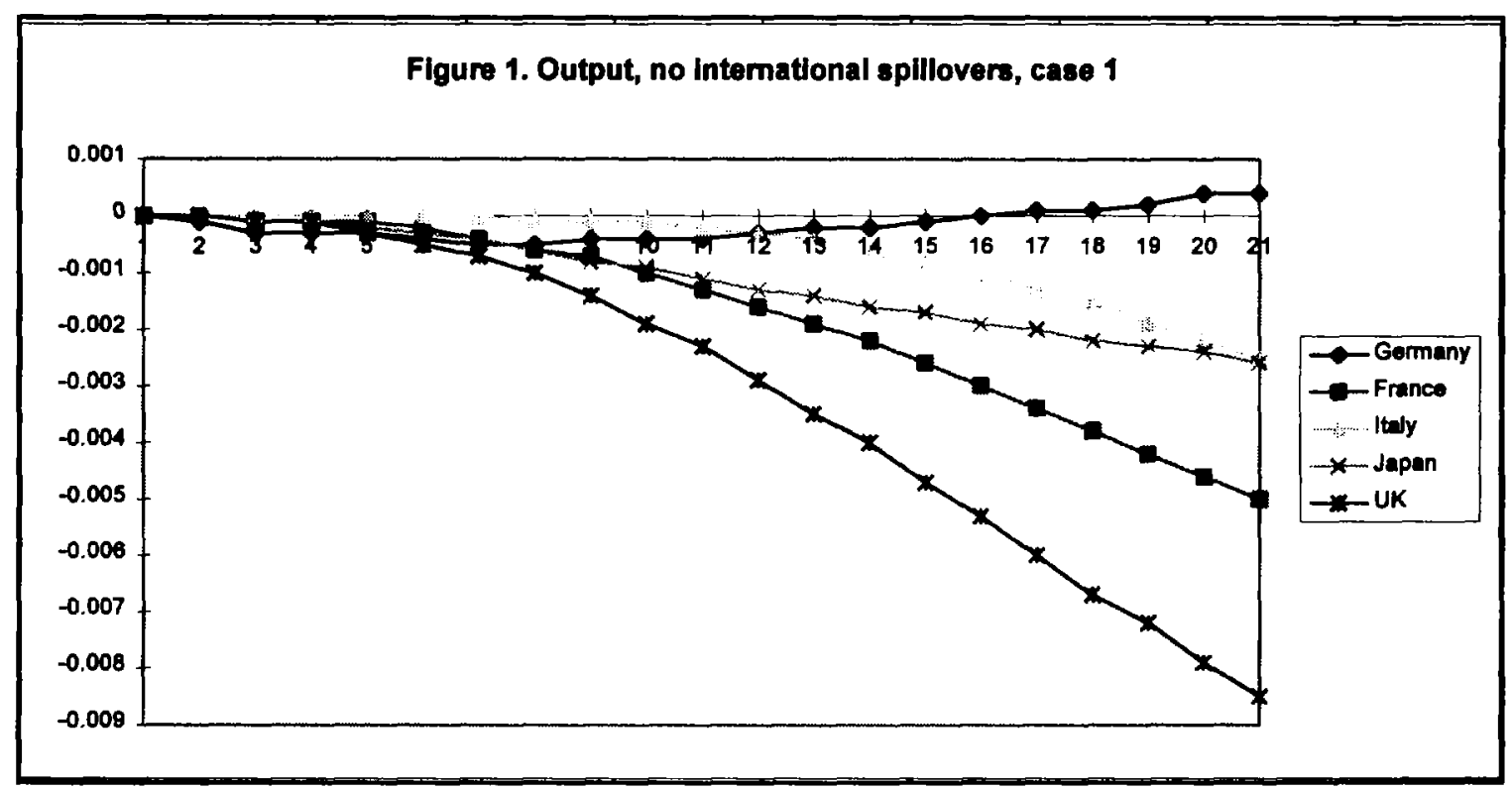

Simulation 1. No trade spillovers in knowledge accumulation; $\beta_{10}=\beta_{14}=0$ As one might have expected the elimination of knowledge diffusion through imports produces a depressing effect on output; however significant country differences emerge: Germany and Italy present negligible output losses (and indeed some minor output gains at the end of the simulation because of lower imports), France and the UK present the most substantial ones with Japan taking an intermediate position. Not surprisingly, France and the UK also suffer the largest relative loss in domestic knowledge accumulation and in export market shares (see table 11). Note, however, that while the UK despecializes relatively more intensively in the science based sector, the relative share loss in France is substantially equiproportional given the constraint on knowledge elasticities obtained in estimation. In general, differences in market share behavior reflect differences in elasticities -as eqs. (13)-(15) show- as well as the different values of the sectoral adjustment speeds. Recall that a fall in $S_{D}$, produces an additional depressing effect on $T$, through the domestic spillover effect, further depressing growth. 
Flgure 2. Output, no Intemational splllovers, case 2

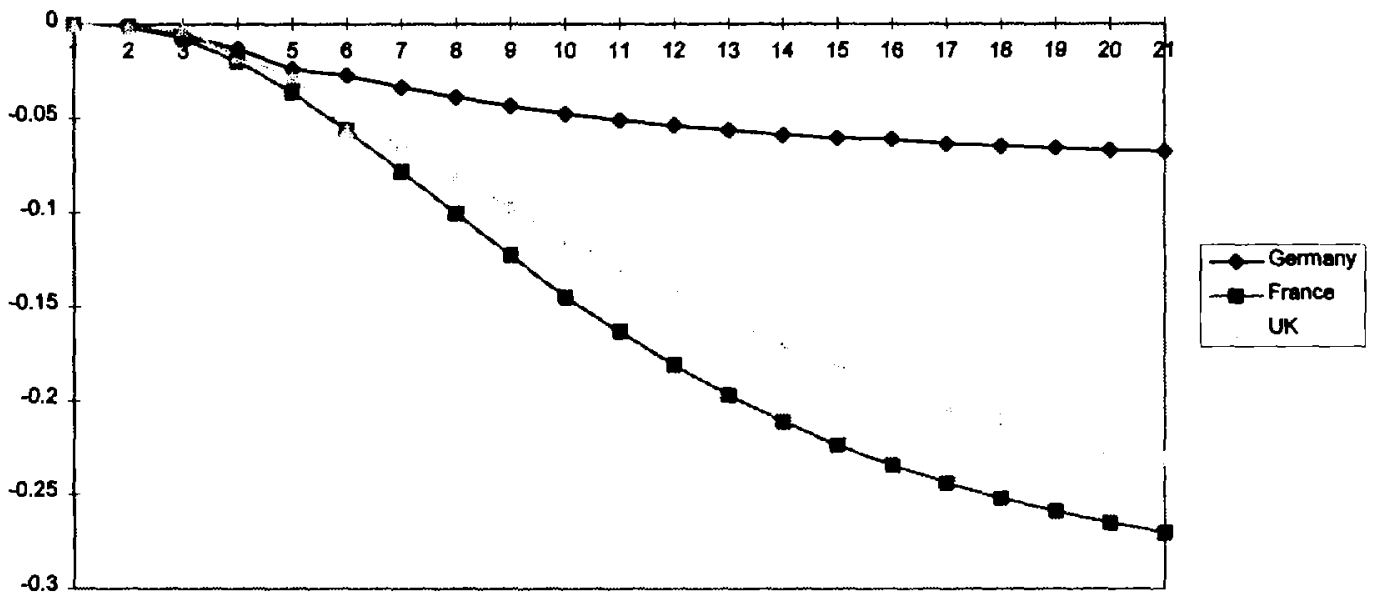

Simulation 2 No international spillovers in knowledge accumulation $\beta_{9}=\beta_{10}=\beta_{14}=0$

In this exercise the second source of knowledge spillover, acting directly through $T_{W}$, is eliminated in addition to the first one . Output losses are reported in fig 3 where the results for Germany on the one hand and for France and the UK on the other look quite different ${ }^{45}$. Table 11 also shows that differences in aggregate performance are reflected in differences in sectoral performance and in the change of the specialization structure as well as in the consequences on domestic knowledge accumulation. These results highlight the consequences of different intensities in "technological integration" on growth. In the previous section we have seen that these differences play a relevant role in the dynamic behavior of the national models.

\footnotetext{
${ }^{45}$ This simulation was not carried out for Italy and Japan as $\beta_{9}$ was set to zero in estimation in these two country cases
} 


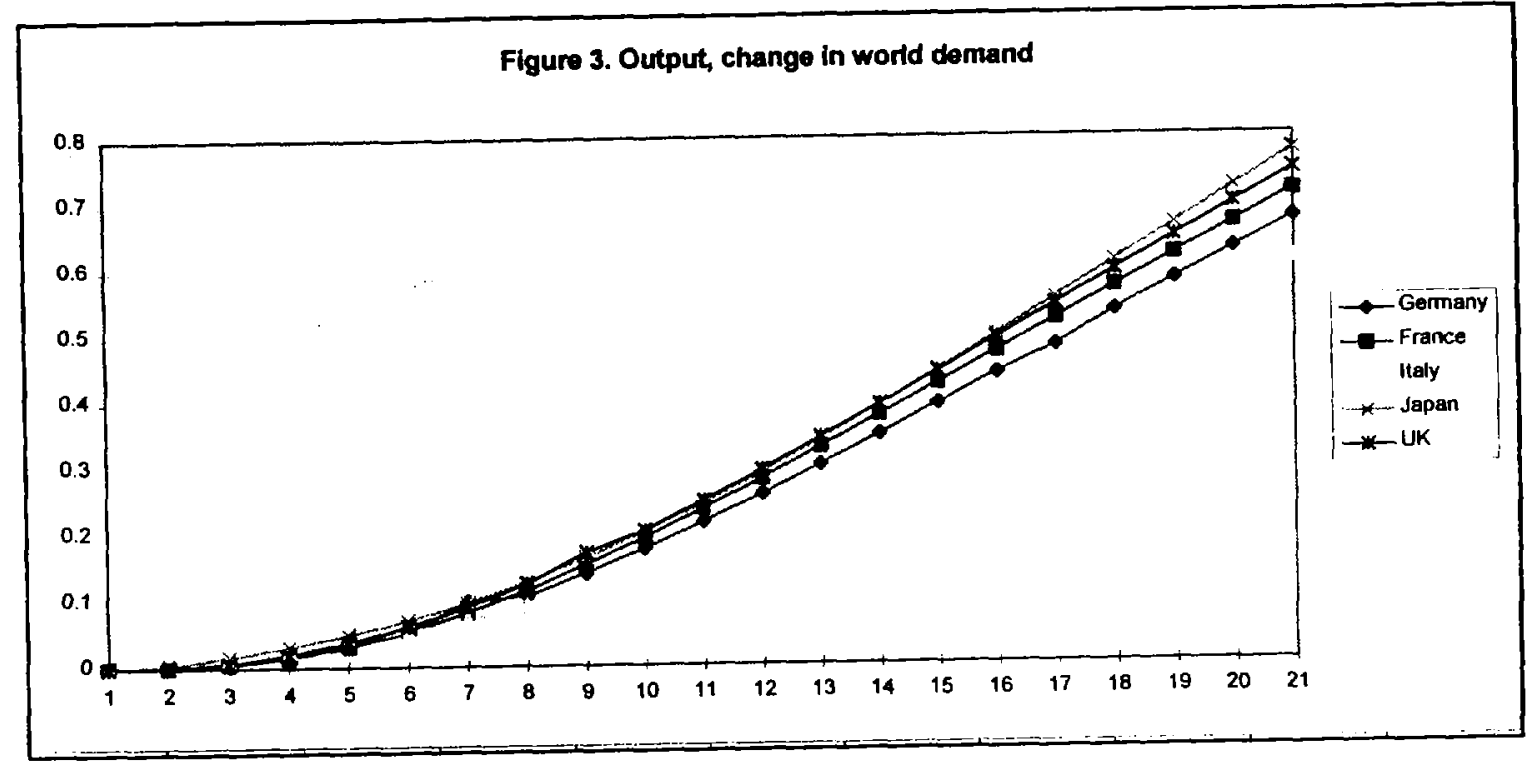

Simulation 3. Absolute and relative change in the rates of growth of sectoral world demand. Traditional no change, Scale Intensive $=$ Science Based $+33 \%$, Specialized Suppliers $+50 \%$ (investment boom).

This simulation explores the consequences of a change in the structure of world demand. Results show that -as para 3 has clarified, see eqs (13)-(15) and (16.1)- market shares and the level of domestic knowledge are not affected by changes in the rates of growth of sectoral world demands (i.e. both export market shares and the level of $T$ take on their base run values in the simulation). We can observe, however, some consequences on output behavior. All countries display increases in output levels, but they do so in different degrees, reflecting their relative specialization -see fig. 3. From eq (20) in para. .3 we know that -if the rates of growth of sectoral world demand increase- the rate of growth of aggregate export share and, ceteris paribus, the rate of growth of output, will increase proportionally to the initial trade specialization structure. Accordingly, the ranking of the output gains in the national cases in descending order is as follows: Japan, United Kingdom, France, Germany, Italy. 


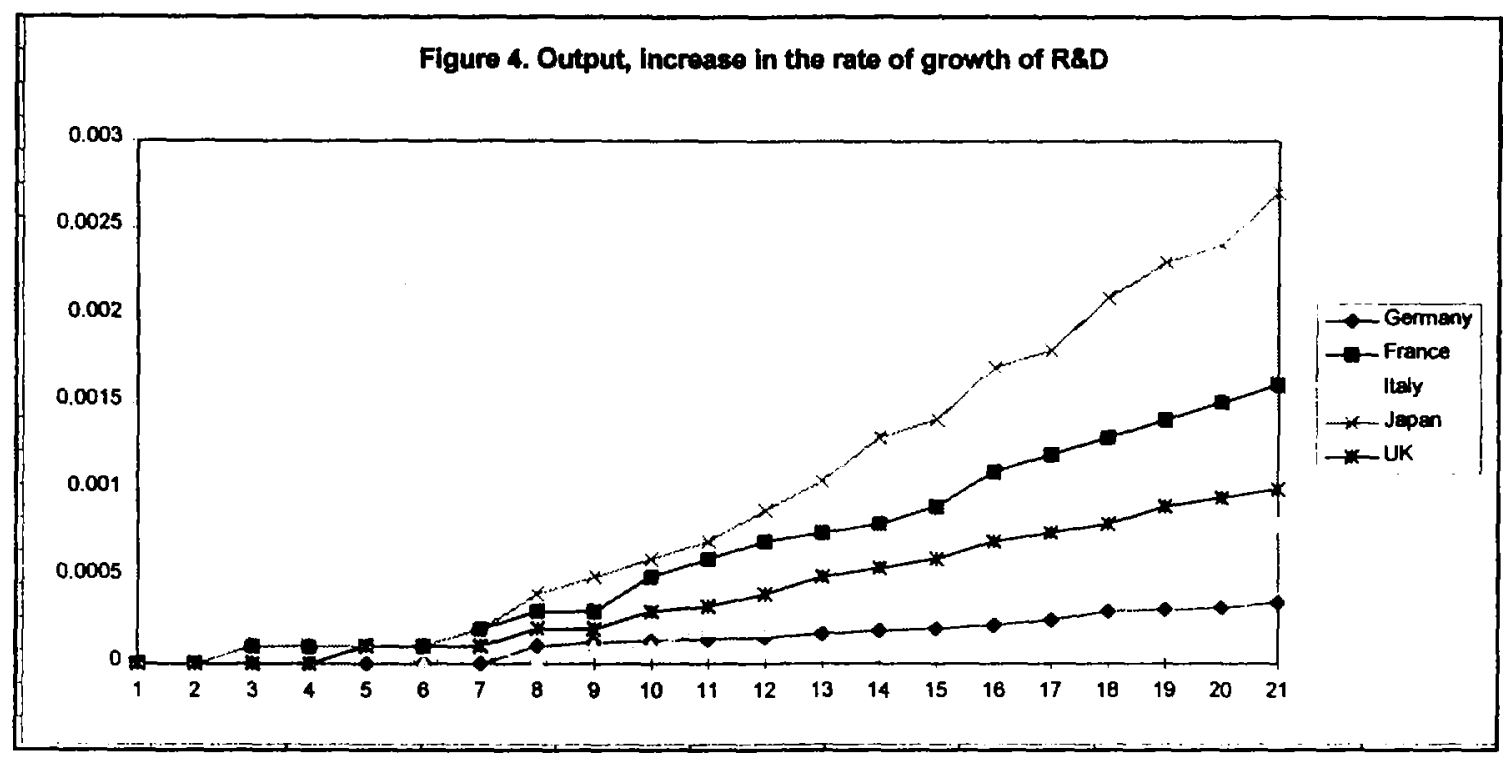

Simulation 4. Doubling of the rate of growth of domestic $R \& D$ (Same for all countries).

All countries benefit in terms of output but, again, with significant differences -see fig 4- with Japan gaining most and Germany and Italy the least. This is only partially the result of Japan's high elasticity of domestic knowledge accumulation to domestic R\&D. Italy, e.g., has a comparable elasticity, resulting in a similar increase in the stock of domestic knowledge, but relatively lower knowledge elasticities in knowledge sensitive sectors as well as a weaker specialization in these sectors. This, from eq. (20), generates a lower rate of growth of the aggregate export share. In addition, contrary to e.g. the case of the UK, which exhibits an even higher increase in the value of $T$ and presents even higher knowledge elasticities, the growth in high tech export shares does not stimulate as large an increase in high tech imports -which depress growth- as the value of $\beta_{14}$ is lower in Japan (and much higher for Italy). Finally in this case too differences in output performances generate differences in the trade specialization structures as this exercise, as other above, modifies the difference between the growth rates of foreign and domestic knowledge and, given eqs. (13)(15) , the rates of growth of sectoral export market shares. 


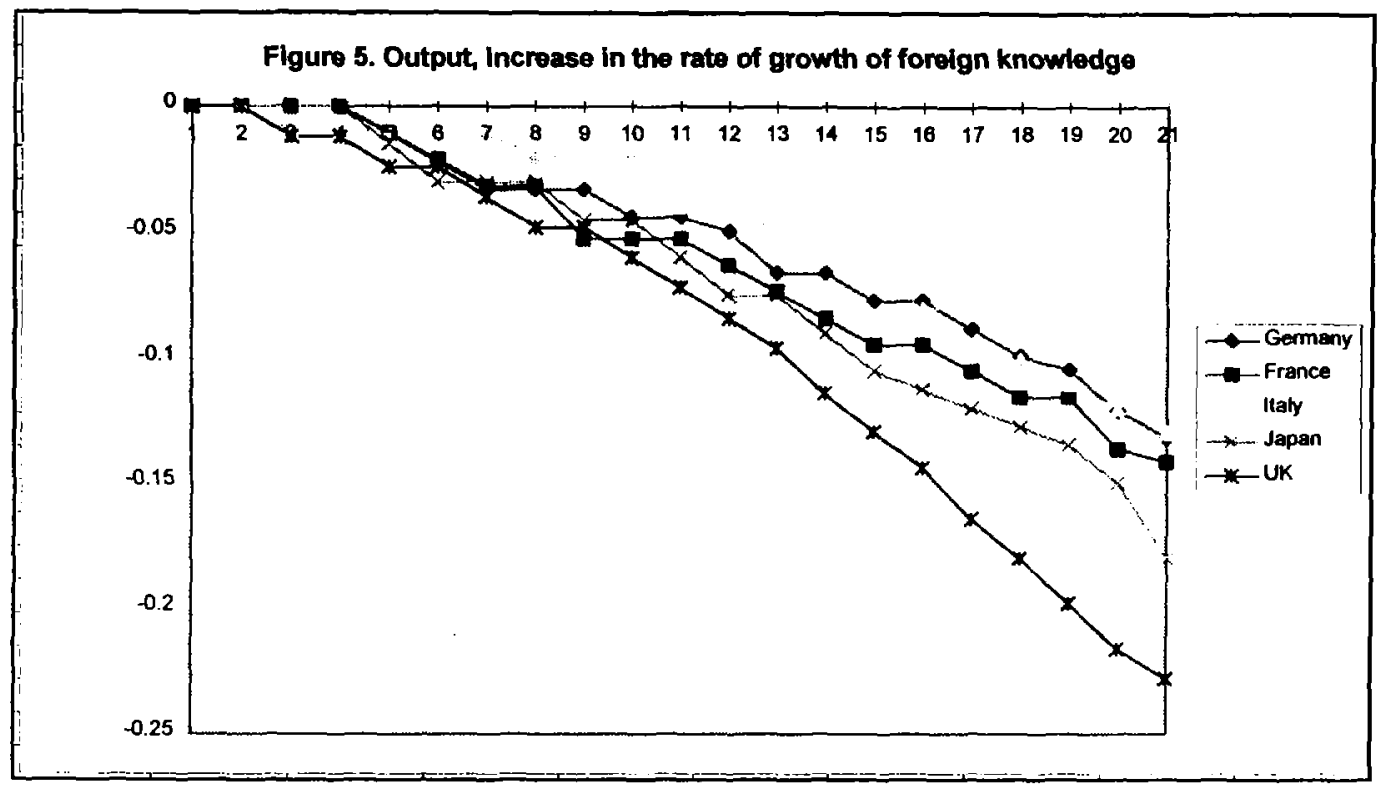

Simulation 5. Doubling the rate of growth of the stock of foreign knowledge. This final simulation allows to appreciate the combined results of the two opposing effects of foreign knowledge on domestic performance: the depressing effect of increased technological competition and the enhancing effect of knowledge diffusion. As shown in fig. 5 the net effect on output is negative in all cases but, once again, with significant national differences. The UK experiences the highest absolute loss followed by Japan. The important difference between these two cases, however, is that the UK also witnesses the highest absolute increase in the stock of domestic knowledge -see table 11- while the net change in the case of Japan is zero. Obviously this is the consequence of the different role that the foreign stock of knowledge plays in knowledge diffusion. Changes in market shares -see table 11- occur in all sectors but are more marked in those where knowledge elasticities are higher. 
Table 11 Percentage changes in market shares and in the level of $T$

\begin{tabular}{|c|c|c|c|c|c|}
\hline & \multicolumn{5}{|c|}{ Simulation 1} \\
\hline & Germany & France & Italy & Japan & UK \\
\hline Sc. Int. & -0.8 & -5.6 & -1.9 & -2.9 & -7.7 \\
\hline Spec. Sup. & -0.7 & -5.2 & -1.9 & -2.7 & -8 \\
\hline Sc. Based & -0.6 & -5.3 & -4.8 & -3.24 & -10.5 \\
\hline \multirow[t]{3}{*}{$\mathrm{T}$} & -5.7 & -6.25 & -5.38 & -4.9 & -10.95 \\
\hline & \multicolumn{5}{|c|}{ Simulation 2} \\
\hline & Germany & France & Italy & Japan & UK \\
\hline Sc. Int. & -10.04 & -27.9 & $\ldots$ & $\ldots$ & -17.3 \\
\hline Spec. Sup. & -7.62 & -27.7 & $\ldots$ & $\ldots$ & -17.3 \\
\hline Sc. Based & -7.62 & -27.9 & $\ldots$ & $\ldots$ & -26.8 \\
\hline \multirow[t]{3}{*}{$\mathrm{T}$} & -10.88 & -32.7 & $\ldots$ & $\ldots$ & -25.7 \\
\hline & \multicolumn{5}{|c|}{ Simulation 4} \\
\hline & Germany & France & Italy & Japan & UK \\
\hline Sc. Int. & 0.5 & 1.8 & 0.56 & 3.7 & 0.9 \\
\hline Spec. Sup. & 0.45 & 1.4 & 0.65 & 2.7 & 1.4 \\
\hline Sc. Based & 0.36 & 1.9 & 0.19 & 3.52 & 1.4 \\
\hline \multirow[t]{3}{*}{$\mathrm{T}$} & 5.4 & 2.05 & 5.47 & 5.6 & 7.7 \\
\hline & \multicolumn{5}{|c|}{ Simulation 5} \\
\hline & Germany & France & Italy & Japan & UK \\
\hline Sc. Int. & -1.7 & -1.5 & -0.8 & -1.8 & -1.7 \\
\hline Spec. Sup. & -1.8 & -1.2 & -0.9 & -1.1 & -1.8 \\
\hline Sc. Based & -1.6 & -1.5 & -2.7 & -1.4 & -2.4 \\
\hline$T$ & 2.2 & 5.7 & 0 & 0 & 7.3 \\
\hline
\end{tabular}

\section{Conclusions}

In this paper we have examined the properties of a dynamic disequilibrium model focused on trade specialization and knowledge accumulation. The sectoral breakdown, which includes four export and two import sectors, follows Pavitt's (1984) taxonomy which is particularly appropriate to deal with empirical analyses of the relationship between innovation activities and production and export performance.

Steady state analysis shows that under perfectly balanced growth which implies no change in trade specialization and a uniform growth of knowledge, international diffusion of knowledge is irrelevant for growth. Unbalanced growth obviously implies changes in the specialization structure; the process of structural change may be enhanced by the effects of domestic spillover on domestic knowledge accumulation as innovation activities in one sector generate positive externalities on the rest of the economy. The analysis also clarifies the ambivalent effect on domestic 
performance of the growth of foreign knowledge as the latter is both a complement and a substitute to domestic knowledge. Whenever these two effects do not perfectly match international knowledge diffusion is associated with unbalanced growth. Unbalanced growth is also associated with "output catching-up", while "technological catching-up" is a necessary but not sufficient condition for the former. The ambivalent effect of the growth of foreign knowledge on domestic knowledge accumulation, trade and growth performance implies that imports of knowledge intensive goods may not lead to higher growth unless this results in sufficiently strong trade performance in the knowledge intensive sectors (i.e. there are thresholds in market share expansion). This result, whose implications for developing countries are relevant, is usually not reported in the literature where higher foreign knowledge accumulation unambiguously leads to higher growth in the country that imports technology through trade.

Parameter estimates have been obtained for Germany, France, Italy, the UK, and Japan. While the results should be considered as preliminary the following points may be singled out: i) results appear to be consistent with theoretical expectations about the importance of "price" and "non price" determinants of trade performance in the four macrosectors; ii) results also seem to be generally consistent with the distribution of revealed comparative advantages (RCA) in the sense that the country cases exhibit high and significant price and/or knowledge elasticities and high adjustment speeds, suggesting a good "capacity to deliver", in sectors where RCA are present; iii) in several cases sectoral price and knowledge elasticities appear to be not significantly different, this indicates that the sectoral disaggregation followed is not always fully relevant, at least from the point of view of export performance; iv) significantly different knowledge elasticities suggest that in all country cases there is a tendency towards a modification in the trade specialization structure in the steady state, however this tendency remains overall moderate; iv) results indicate relevant country differences in the process of knowledge accumulation and different degrees of exposure to international knowledge diffusion.

Stability and sensitivity analyses yield further information about the robustness of the specialization structures. In two country cases, one unstable root suggests that, over the long run (which from simulations appears to be around 40 years), the specialization structure would not be sustainable. This effect could be eliminated by a deeper technological 
integration which would compensate the inadequate domestic knowledge accumulation.

Simulation exercises confirm steady state results on the relevance of country differences in trade specialization and in domestic knowledge accumulation in affecting growth, and they also clarify the relationship between growth and changes in the structure of trade specialization.

Further lines of investigation can be developed from the present framework, some of which are the following. The application of this approach to developing economies suggests, if only because of data availability, a limitation of the number of sectors, but also a different formulation of the mechanism of domestic knowledge accumulation and diffusion as well as a different empirical implementation ${ }^{46}$, (keeping in mind that the exploitation of knowledge diffusion per se requires a certain amount of domestic knowledge accumulation even in technologically lagging economies).

If data availability is not a problem, however, as is the case for the larger developed economies, the implications of sectoral knowledge accumulation processes and their interaction should be explored.

Finally, both in the case of developed and of developing countries, the remaining components of the balance of payments should be explicitly considered in determining long run growth.

\footnotetext{
${ }^{46}$ In particular, knowledge accumulation in developing countries is only partially, if at all, captured by patenting. See Freeman and Hagedoorm (1994).
} 


\section{References}

Abramovitz, M.A. 1986. "Catching Up, Forging, and Falling Behind." Journal of Economic History 46:385-406.

Amable, B., and B. Verspagen. 1995. "The Role of Technology in Market Shares Dynamics." Applied Economics 27:197-204.

Amendola, G., P. Guerrieri, and P.C. Padoan. 1992. "International Patterns of Technological Accumulation and Trade." Journal of International and Comparative Economics 1:173-97.

Archibugi D., and J. Michie. 1995. "The Globalization of Technology: A New Taxonomy." Cambridge Journal of Economics 19:121-40.

Bell, M. , and K. Pavitt. 1995. "The Development of Technological Capabilities." In I. ul Haque and others, Trade, Technology, and International Competitiveness. Washington, DC: World Bank.

Ben-David, D., and M. Loewy. 1995. "Free Trade and Long-Run Growth." CEPR Working Paper 1183.

Carter, R.A.L., and A.L. Nagar. 1977. "Coefficients of Correlation for Simultaneous Equations Systems." Journal of Econometrics 6:39-50.

Consiglio Nazionale delle Ricerche. 1992. Economic, $R \& D$, and Patent Indicators of the Seven Major Countries, 1970-91. Rome: Istituto di Studi sulla Documentazione Scientifica.

Coe, D., and E. Helpman. 1993. "International R\&D Spillovers." NBER Working Paper 4444.

Coe, D., E. Helpman,. and A. Hoffmeister. 1994. "North-South R\&D Spillovers." IMF Working Paper 94/144. 
De Arcangelis, G., G. Gandolfo, P.C. Padoan, and C. Wymer . 1996. "Nonlinear Estimation of a Non-linear Dynamic Model." In A. Barnett, G. Gandolfo, and H. Hillinger, eds., Dynamic Disequilibrium Modelling. Cambridge, Mass.: Cambridge University Press.

Dosi , G. , K. Pavitt, and L. Soete,. 1990. The Economics of Technological Change and International Trade. Brighton: Wheatsheaf.

Fagerberg, J. 1988. "International Competitiveness." Economic Journal 98:355-74.

Fagerberg, J. 1994. "Technology and International Differences in Growth Rates." Journal of Economic Literature XXXII: 1147-75.

Freeman, C. , and J. Hagedoorn. 1994. "Catching Up or Falling Behind: Patterns in International Inter-Firm Technology Partnering." World Development 22:771-80.

Gandolfo, G. 1981. Qualitative Analysis and Econometric Estimation of Continuous Time Dynamic Models. Amsterdam: North Holland.

Gandolfo, G. 1996. Economic Dynamics. 3rd revised edition. New York: Springer Verlag.

Gandolfo, G., and P.C. Padoan. 1984. A Disequilibrium Model of Real and Financial Accumulation in an Open Economy. Berlin, Heidelberg, New York, Tokyo: Spinger-Verlag.

Grossman, G.M., and E. Helpman. 1989. "Growth and Welfare in a Small Open Economy.” NBER Working Paper 2970.

Grossman, G.M., and E. Helpman. 1990. "Comparative Advantage and Long Run Growth." American Economic Review 80: 796-815.

Keller, W. 1995. “International R\&D Spillovers and Intersectoral Trade Flows: Do They Match? Yale University. Mimeo. 
Keller, W. 1996. "Are International R\&D Spillovers Trade-related? Analyzing Spillovers among Randomly Matched Trade Partners. University of Wisconsin-Madison. Mimeo.

Magnier, A., and J. Toujias-Bernate. 1994. "Technology and Trade: Empirical Evidences for the Major Five Industrialized Countries." Weltwirstschaftliches Archiv band 130 heft 3: 494-520.

Nelson, R.R., ed. 1993. National Innovation Systems. New York: Oxford University Press.

Pasinetti, L.L. 1981. Structural Change and Economic Growth. Cambridge Mass.: Harvard University Press.

Pavitt, K. 1984. Sectoral Patterns of Technical Change: Towards a Taxonomy and a Theory. Research Policy 13:343-75.

Perez T. 1995. "Imprese Multinazionali e Diffusione Internazionale della Tecnologia." University of Ancona. Unpublished Ph.D. thesis.

Romer, P. 1990. "Endogenous Technological Change. Journal of Political Economy 98:S71-S102.

Verspagen, B. 1993. Uneven Growth Between Interdependent Economies. Aldershot: Avebury. 


\section{Appendix 1 Derivation of the Steady State}

In this Appendix we develop the solution of the steady state for model

(1)-(11), following the method of undetermined coefficients (see Gandolfo 1996).

We assume, for the exogenous variables

$$
\begin{aligned}
& \mathrm{T}_{\mathrm{w}}=T_{w}^{(j} e^{\lambda \prime} \\
& W=W^{o} e^{\lambda_{\| \prime}} \\
& W_{i}=W_{i}^{\prime} e^{\lambda_{1} \prime} \\
& P_{X}=P_{X}^{(} e^{\lambda_{p x}{ }^{\prime}} \\
& P_{\lambda_{1}}=P_{M}^{\prime \prime} e^{\lambda_{t m}{ }^{\prime}} \\
& F=F^{\prime \prime} e^{\lambda_{t}{ }^{\prime}} \\
& P=P^{\prime} e^{\lambda_{r}+1}
\end{aligned}
$$

and for the endogenous variables

$$
\begin{aligned}
& S_{A}=S_{A}^{*} e^{p .1} \text { ' } \\
& S_{B}=S_{B \beta}^{*} e^{\mathcal{\rho}_{H}} \\
& S_{c}=S_{c}^{*} \cdot e^{p_{c} \cdot t} \\
& S_{l)}=S_{1)}^{*} e^{\rho_{1 \prime}} \text { ' } \\
& S_{X}=S_{X}^{*} e^{\mathcal{\rho}_{X}}, \\
& T=T^{\prime} e^{\mathfrak{\rho}_{T}}{ }^{\prime} \\
& S_{M I}=S_{M I}^{*} e^{\rho_{l .}} \\
& S_{M H}=S_{M H}^{*} e^{\rho_{I I}}, \\
& S_{M}=S_{M}^{*} e^{\rho_{M}} \\
& S_{X H}=S_{X H}^{\cdot} e^{\rho} x \prime^{\prime} \\
& Y=Y^{*} e^{\rho_{1}}
\end{aligned}
$$

by substituting in eqs. (1) - (11) we obtain 


$$
\begin{aligned}
& \rho_{A}=\alpha_{2}\left\{\log \gamma_{1}-\beta_{1} \log P^{O}-\log S_{A}^{*}\right\} \text { (A.1) } \\
& \rho_{B}=\alpha_{3}\left\{\log \gamma_{2}-\beta_{2} \log P^{o}-\beta_{3} \log T_{W}^{o}-\beta_{3} \lambda_{T} t+\beta_{3} \log T^{*}+\beta_{3} \rho_{T} t-\log S_{B}^{*}-\rho_{B} t\right\} \text { (A.2) } \\
& \rho_{c}=\alpha_{4}\left\{\log \gamma_{3}-\beta_{4} \log P^{0}-\beta_{5} \log T_{W}^{o}-\beta_{5} \lambda_{T} t+\beta_{5} \log T^{*}+\beta_{5} \rho_{T} t-\log S_{c}^{*}-\rho_{c} t\right\} \text { (A.3) } \\
& \rho_{D}=\alpha_{5}\left\{\log \gamma_{4}-\beta_{6} \log T_{W}^{()}-\beta_{6} \lambda_{T} t+\beta_{6} \log T^{*}+\beta_{6} \rho_{T^{t}}-\log S_{D}^{*}\right\} \text { (A.4) } \\
& \rho_{r}=\alpha_{6}\left\{\log \gamma_{5}+\beta_{7} \log F^{O}+\beta_{8} \log S_{D}^{*}+\beta_{8} \rho_{D} t-\log T^{*}-\rho_{7} t\right\}+\beta_{9} \log T_{W}^{()} \\
& +\beta_{9} \lambda_{T} t+\beta_{10} \log S_{M H}^{*}+\beta_{10} \rho_{H} t(A .5) \\
& \rho_{X}=\left(\rho_{A}+\lambda_{A}\right)\left(S_{A}^{*} / S_{X}^{*}\right)\left(W_{A}^{0} / W^{0}\right) e^{\left(\rho_{A}-\rho_{X}+\lambda_{A}-\lambda_{I I}\right) t} \\
& +\left(\rho_{B}+\lambda_{B A}\right)\left(S_{B}^{*} / S_{X}^{*}\right)\left(W_{B}^{o} / W^{o}\right) e^{\left(\rho_{B 1}-\rho_{X}+\lambda_{B}-\lambda_{H}\right) r} \\
& +\left(\rho_{c}+\lambda_{c}\right)\left(S_{C}^{*} / S_{X}^{*}\right)\left(W_{c}^{0} / W^{0}\right) e^{\left(\rho_{c}-\rho_{x}+\lambda_{c}-\lambda_{H}\right) r} \\
& +\left(\rho_{D}+\lambda_{l}\right)\left(S_{D}^{*} / S_{X}^{*}\right)\left(W_{D}^{0} / W^{o}\right) e^{\left(\rho_{D}-\rho_{X}+\lambda_{D}-\lambda_{W}\right) \prime}-\lambda_{W} \\
& \rho_{L}=\alpha_{7}\left\{\log \gamma_{0}+\beta_{11} \log P^{O}-\rho_{L} t-\log S_{M L}^{*}\right\} \text { (A.7) } \\
& \rho_{H}=\alpha_{8}\left\{\log \gamma_{7}+\beta_{12} \log P^{()}-\beta_{13} \log T^{*}-\beta_{13} \rho_{t} t+\beta_{13} \log T_{w}^{()}\right. \\
& \left.+\beta_{13} \lambda_{T} t+\beta_{14} \log S_{X H}^{*}+\beta_{14} \rho_{X H} t-\log S_{M H}^{*} t-\rho_{H} t\right\}(A .8) \\
& \rho_{M}=\rho_{L}\left(S_{M L}^{*} / S_{M}^{*}\right) e^{\left(\rho_{t}-\rho_{M}\right) t}+\rho_{M}\left(S_{M H}^{*} / S_{M}^{*}\right) e^{\left(\rho_{I I}-\rho_{M}\right) t}(A .9)
\end{aligned}
$$

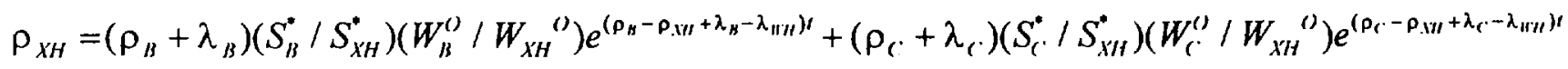

$$
\begin{aligned}
& +\left(\rho_{D}+\lambda_{l}\right)\left(S_{l)}^{*} / S_{Y H}^{*}\right)\left(W_{D}^{(0)} / W_{X H}{ }^{o}\right) e^{\left(\rho_{D}-\rho_{X I}+\lambda_{D}-\lambda_{H H}\right) \prime}-\lambda_{H}(A .10) \\
& \rho_{Y}=\alpha_{1}\left\{\log W^{(0)}+\lambda_{W} t+\log P_{X}{ }^{0}+\lambda_{P_{X}} t-\log P_{M}{ }^{0}-\lambda_{r^{\prime} m} t+\log S_{X}^{*}+\rho_{X} t\right. \\
& \left.-\log S_{M}^{\prime \prime}-\rho_{M^{l}}-\log Y^{*}-\rho_{Y} t\right\}(A .11)
\end{aligned}
$$

The steady state solution implies solving for the steady state growth rates and for the steady state initial values (the * values). The first set of solutions (growth rates) implies considering the elements containing $t$ in eqs.(A.1)-(A.11) and setting them to zero. Since this part of the exercise delivers useful information a bout the properties of the model it is discussed in the text, para. 3. The solution for the steady state initial values implies considering the following set of equations: 


$$
\begin{aligned}
& \log S_{A}^{*}=\left\{\log \gamma_{1}-\beta_{1} \log P^{O}\right\}-\rho_{A} / \alpha_{2} \text { (A.12) } \\
& \log S_{B}^{*}=\left\{\log \gamma_{2}-\beta_{2} \log P^{o}-\beta_{3} \log T_{W}^{o}+\beta_{3} \log T^{*}\right)-\rho_{C} / \alpha_{3} \text { (A.13) } \\
& \log S_{\mathrm{C}}^{*}=\left\{\log \gamma_{3}-\beta_{4} \log P^{()}-\beta_{5} \log T_{w}^{()}+\beta_{5} \log T^{*}\right\}-\rho_{C} / \alpha_{4}(A .14) \\
& \log S_{D}^{*}=\left\{\log \gamma_{4}-\beta_{6} \log T_{w}^{O}+\beta_{6} \log T^{*}\right\}-\rho_{D} / \alpha_{5} \text { (A.15) } \\
& \log T^{*}=\left\{\log \gamma_{5}+\beta_{7} \log F^{()}+\beta_{8} \log S_{D}^{*}\right\}+\left(\beta_{9} \log T_{W}^{()}\right. \\
& \left.+\beta_{10} \log S_{M H}^{*}-\rho_{T}\right) / \alpha_{6}(A .16) \\
& S_{X}^{*}=\left[\left(\rho_{A}+\lambda_{A}\right) S_{A}^{*}\right)\left(W_{A}^{O} / W^{0}\right)+\left(\rho_{B}+\lambda_{B A}\right) S_{B}^{*}\left(W_{B}^{O} / W^{O}\right) \\
& \left.+\left(\rho_{c}+\lambda_{c}\right) S_{c}^{*}\left(W_{c}^{()} / W^{0}\right)+\left(\rho_{D}+\lambda_{b}\right) S_{b}^{*}\left(W_{D}^{0} / W^{(0}\right)\right]\left(\rho_{X}+\lambda_{w}\right)(A .17) \\
& \log S_{M L}^{*}=\left\{\log \gamma_{6}+\beta_{11} \log P^{\prime \prime}\right\}-\rho_{L} / \alpha,(A .18) \\
& \log S_{M H}^{*}=\left\{\log \gamma_{7}+\beta_{12} \log P^{()}-\beta_{13} \log T^{*}+\beta_{13} \log T_{W}^{()}\right. \\
& \left.+\beta_{14} \log S_{X H}^{*}+\right\}-\rho_{H} / \alpha_{8}(A .19) \\
& S_{A^{*}}^{*}=\rho_{I .} S_{M I}^{*}+\rho_{M^{\prime}} S_{M H}^{*}(A .20) \\
& S_{Y H}^{*}=\left[\left(\rho_{H}+\lambda_{B}\right) S_{B}^{*}\left(W_{B}^{(0} / W_{X H}{ }^{o}\right)+\left(\rho_{C}+\lambda_{C}\right) S_{C}^{*}\left(W_{C}^{0} / W_{X H}{ }^{0}\right)\right. \\
& \left.+\left(\rho_{D}+\lambda_{D}\right) S_{D}^{*}\left(W_{D}^{()} / W_{X H}{ }^{\prime \prime}\right)\right] /\left(\rho_{X H}+\lambda_{H}\right)(A .21) \\
& \log Y^{*}=\left\{\log W^{\prime \prime}+\log P_{X}{ }^{\prime}-\log P_{M}{ }^{\prime}+\log S_{X}^{*}\right. \\
& \left.-\log S_{M}^{*}\right\}-\rho_{Y} / \alpha_{1}(A .22)
\end{aligned}
$$

The set of non linear eqs. (A.12)-(A.22) can be used to solve for the initial level of the endogenous variables. The rather tedious calculations are not reported here. The solution for the starred values are then used to linearize the non linear-model (1)-(11) and perform the stability analysis described in para 5 . 


\section{Appendix 2. Data sources and definitions}

Data for exports and imports grouped according to Pavitt's (1984) in nominal terms were partly provided by the Italian Institute for Foreign Trade (ICE) and partly elaborated by the author on the NIMEXE data base (Eurostat). The "world" aggregate includes: United States, Japan, Germany, France, Italy, United Kingdom. A detailed classification is available on request from the author. They have been transformed in constant dollar values at 1985 GDP price indices and 1985 PPP dollar exchange rates.

The stock of domestic knowledge $T$ is the fractional patent count taken from the US Patent and Trademark Office cumulated on a benchmark initial value.

The stock of foreign knowledge $T_{W}$ is defined as $T$ but it includes the sum of patent counts for the countries entering the group defined above less the patent counts for the domestic economy.

$P$ is the real effective exchange rate (source Bank of Italy)

$F$ is the amount of private $\mathrm{R} \& \mathrm{D}$ expenditure transformed in constant dollar values at 1985 GDP price indices and 1985 PPP dollar exchange rates, cumulated on a benchmark initial value and depreciated at the rate of 15 percent a year. (source CNR 1992)

The sample period (annual observations) covers 1970-1991. All stocks were measured at the end of period while prices are period averages. All series measured at the end of period were adjusted in order to be consistent with flow data (Gandolfo 1981., equations (30) and (31) of chapter 3). This allows to consider variables which contain both stocks and flows in their definition. The approximate discrete analogue to the continuous model used for the estimation carried out in section 4 was obtained as expounded in Gandolfo (1981) , chapter 3 paragraph 3.2.2 

Title

WPS1665 How Important Are Labor Markets to the Welfare of Indonesia's Poor?

WPS1666 is Growth in Bangladesh's Rice Production Sustainable?

WPS1667 Dealing with Commodity Price Uncertainty

WPS1668 Small is Beautiful: Preferential Trade Agreements and the Impact of Country Size, Markel Share. Efficiency, and Trade Policy

WPS1669 International Capital Flows: Do Short-Term Investment and Direct Investment Differ?

WPS1670 Assessing the Welfare Impacts of Public Spending

WPS1671 Financial Constraints, Uses of Funds, and Firm Growth: An International Comparison

WPS1672 Controlling Industrial Pollution: A New Paradigm

WPS1673 Indonesian Labor Legislation in a Comparative Perspective: A Study of Six APEC Countries

WPS1674 How Can China Provide Income Security for Its Rapidly Aging Population?

WPS1675 Nations, Conglomerates, and Empires: The Tradeoff between Income and Sovereignty

WPS1676 The Evolution of Payments in Europe, Japan, and the United States: Lessons for Emerging Market Economies

WPS1677 Reforming Indonesia's Pension System
Author

Andrew D. Mason

Jacqueline Baptist

John Baffes

Madhur Gautam

Panos Varangis

Don Larson

Maurice Schiff

Punam Chuhan

Gabriel Perez-Quiros

Helen Popper

Dominique van de Walle

Asli Demirgüç-Kunt

Vojislav Maksimovic

Shakeb Afsah

Bemoit Laplante

David Wheeler

Reema Nayar

Barry Friedman

Estelle James

Cheikh Kane

Monika Queisser

Branko Milanovic

David B. Humphrey

Setsuya Sato

Masayoshi Tsurumi

Jukka M. Vesala

Chad Leechor
Date

October 1996

October 1996

October 1996

October 1996

October 1996

T. Nadora 33925

October 1996

October 1996

October 1996

D. Wheeler

33401

October 1996

R. Nayar 33468

October 1996

S. Khan 33651

October 1996

S. Khan 33651

October 1996

T. Ishibe 38968

October 1996
G. Telahun 82407 


\section{Policy Research Working Paper Series}

Title

WPS1678 Financial Development and Economic Ross Levine Growth: Views and Agenda

WPS1679 Trade and the Accumulation and Diffusion of Knowledge
Contact

Date

October 1996

Pier Carlo Padoan

November 1996

39515 